\title{
THE AGE OF PHARMACEUTICAL 3D PRINTING. TECHNOLOGICAL AND THERAPEUTICAL IMPLICATIONS OF ADDITIVE MANUFACTURING.
}

\author{
ION-BOGDAN DUMITRESCU ${ }^{1}$, DUMITRU LUPULIASA ${ }^{2}$, CRISTINA MANUELA DRĂGOI ${ }^{3 *}$, \\ ALINA CRENGUȚA NICOLAE ${ }^{3}$, ANCA POP $^{4}$, GABRIEL ȘARAMET $^{2}$, DOINA DRĂGĂNESCU ${ }^{1}$ \\ I "Carol Davila" University of Medicine and Pharmacy, Faculty of Pharmacy, Physics and Informatics Department, Bucharest, \\ Romania \\ 2 "Carol Davila" University of Medicine and Pharmacy, Faculty of Pharmacy, Pharmaceutical Technology Department, \\ Bucharest, Romania \\ 3 "Carol Davila” University of Medicine and Pharmacy, Faculty of Pharmacy, Biochemistry Department, Bucharest, Romania \\ 4 “Iuliu Hațieganu” University of Medicine and Pharmacy, Faculty of Pharmacy, Department of Toxicology, Cluj-Napoca, \\ Romania
}

*corresponding author: cristina.dragoi@umfcd.ro

Manuscript received: January 2018

\begin{abstract}
Additive manufacturing technologies have been adopted by various industries in the past decades, but since the approval of the first 3D printed drug in 2015 by the US Food and Drug Administration, pharmaceutical research has shown ever growing interest in the subject as well. The 3D printing technologies adapted for pharmaceutical applications will be reviewed and important research results will be documented. The most significant advantages when using 3D printing technologies are the ability of creating highly personalised drug products and also the ability to easily alter the drug release characteristics. Medicine and pharmacy university curriculums should be updated with courses on 3D modelling software and 3D printing technologies, as these methods promise great progress for the future of healthcare.
\end{abstract}

\section{Rezumat}

Metodele de fabricație aditivă au fost adoptate în diferite industrii în ultimele decenii, însă de la aprobarea primului medicament tipărit 3D, în anul 2015, de către Food and Drug Administration în SUA, cercetarea farmaceutică a dezvoltat un interes tot mai accentuat pentru acest subiect. Tehnologiile de imprimare 3D, adaptate aplicațiilor farmaceutice, vor fi discutate în detaliu și vor fi documentate rezultatele importante obținute în acest domeniu. Principalele avantaje în utilizarea tehnologiilor de imprimare 3D sunt abilitatea de a crea produse farmaceutice înalt personalizate şi, de asemenea, capacitatea de a modifica cu ușurință caracteristicile de eliberare ale substanței farmacologic active. În programele de învățământ ale universităților de medicină și farmacie ar trebui să fie adăugate cursuri de modelare 3D și de aprofundare a tehnologiilor de imprimare 3D, deoarece aceste metode promit progrese importante în domeniul medicinei personalizate.

Keywords: pharmaceutical 3D printing, additive manufacturing, drug manufacturing, personalised treatment

\section{Introduction}

The terms additive manufacturing (AM) and three dimensional printing (3DP) are considered similar by the British Standards Institution [104] and are used interchangeably throughout this article. Although AM is sometimes preferred, when referred to as a pharmaceutical term, it might create confusion either to additives or excipients, either to additive processes such as tablet coating or capsule filling [73]. Emanuel Sachs, the Massachusetts Institute of Technology researcher who introduced the $3 D$ printing term for the binder jetting method, recollects in a radio recording that he received all but negative feedback from his peers, yet finally insisted on using this term due to his family history in book publishing [3].

Recent innovations have been possible due to the implementation of novel 3DP methods in diverse industries, from aerospace to medical, dental, biomedical and indeed pharmacy [43].

Additive manufacturing includes multiple and different processes that allow objects to be produced, but all of them use digital 3D models in different file formats, with the exception of penbased 3D printing [12,30,42,73], for which $3 D$ writing could be a more appropriate term.

Although previous industrial revolutions focused on mass manufacturing, 3D printing may be a counterrevolution, shifting towards smaller batch sizes or even unique, on-demand, personalised, yet reasonably priced products and medicine and pharmacy are two areas that would benefit considerably $[80,115]$.

Among the first healthcare related uses of $3 \mathrm{D}$ printing were anatomical models used for diagnosis and for planning complex surgeries, culminating 
nowadays in various dentistry applications (dental bridges, crown and braces), custom prosthetics, artificial orthopaedic implants, body-conformal hearing aids, tissue manufacturing, regenerative medicine and drug products $[32,77,80,91,115]$.

Almost seventy years since the introduction of Spansule, the first extended release formulation, attention has shifted towards new manufacturing techniques and personalising these formulations according to the individual patient needs [78], keeping in mind that $70 \%$ of current oral medicines are immediate release formulations [93].

$3 \mathrm{D}$ bioprinting refers to methods that employ living cells [108], and while the main advantage of biomedical manufactured scaffolds is the proliferation of living cells, from a pharmaceutical point of view they can also be a source for drug delivery [115], with antimicrobial drug-eluting implants as an example [65]. Current research includes DNA synthesizing proteins experimentation, organ and live tissues printing for medical testing [80]. Using stem cells in 3D organ and printing could be the path to full organ reconstruction [80].

Every occurrence of ink in this review refers to the liquid or semisolid materials used for 3DP, unless otherwise specified.
Some authors introduced and use the term printlet for a 3D printed solid oral dosage form $[36,37,106]$.

The review will continue with a brief description of the general 3DP techniques and then focus on those relevant for pharmaceutical applications, as reported in the scientific literature.

\section{General 3DP methods}

In opposition to formative methods (injection moulding or casting) and subtractive ones (drilling or turning), additive manufacturing consists in the processes of producing an object layer upon layer: sequential layers of liquid, powder or solid materials are placed and cured one on top of the other $[12,42,48,89,115]$, with the recent exception of CLIP (Continuous Liquid Interface Production) [48].

Although some of the substrate materials can be particular to a single $3 \mathrm{D}$ printing process, the most significant difference among these methods is the material deposition procedure [115].

The resolution of the printed product is defined differently depending on the method used: for example, layer thickness and nozzle diameter are relevant in Fused Deposition Modelling (FDM), but laser spot size is relevant in Selective Laser Sintering (SLS) [89].

\begin{tabular}{|c|c|c|c|}
\hline 3DP Method & Technologies & Traditional materials & $\begin{array}{c}\text { Adapted for } \\
\text { pharmaceutical research }\end{array}$ \\
\hline \multirow{2}{*}{ Extrusion } & $\begin{array}{l}\text { FDM* or FFF* } \\
\text { Fused Deposition Modelling or } \\
\text { Fused Filament Fabrication }\end{array}$ & $\begin{array}{l}\text { Thermoplastic polymer } \\
\text { filament }\end{array}$ & Yes $[24,62,73,77,115]$ \\
\hline & $\begin{array}{c}\text { PAM } \\
\text { Pressure Assisted Microsyringe }\end{array}$ & Liquid/semisolid materials & Yes $[43,77,115]$ \\
\hline Binder Jetting & $\begin{array}{c}\text { BJ } \\
\text { Binder Jetting }\end{array}$ & $\begin{array}{l}\text { Polymer powders, sand, } \\
\text { ceramic and metal powders }\end{array}$ & Yes $[6,62,115]$ \\
\hline Material Jetting & $\begin{array}{c}\text { DoD } \\
\text { Drop on Demand / Drop on Drop }\end{array}$ & $\begin{array}{l}\text { Liquid (photo)polymers, waxy } \\
\text { polymers }\end{array}$ & Yes $[46,57,62]$ \\
\hline \multirow{3}{*}{ Photopolymerisation } & $\begin{array}{c}\text { SLA** } \\
\text { Stereolithography }\end{array}$ & \multirow{3}{*}{ Liquid photopolymers } & Yes $[32,62,73,77,115]$ \\
\hline & $\begin{array}{c}\text { DLP } \\
\text { Direct/Digital Light Processing }\end{array}$ & & Yes [20] \\
\hline & $\begin{array}{c}\text { CLIP** } \\
\text { Continuous Liquid Interface Production }\end{array}$ & & Not found \\
\hline \multirow{4}{*}{ Powder Bed Fusion } & $\begin{array}{c}\text { SLS } \\
\text { Selective Laser Sintering }\end{array}$ & $\begin{array}{l}\text { Thermoplastic polymer powder, } \\
\text { ceramic powder }\end{array}$ & Yes $[24,57,62]$ \\
\hline & $\begin{array}{c}\text { DMLS } \\
\text { Direct Metal Laser Sintering }\end{array}$ & \multirow{3}{*}{ Metal powders } & Not found \\
\hline & $\begin{array}{c}\text { SLM } \\
\text { Selective Laser Melting }\end{array}$ & & Not found \\
\hline & $\begin{array}{c}\text { EBM } \\
\text { Electron Beam Melting }\end{array}$ & & Not found \\
\hline
\end{tabular}


FARMACIA, 2018, Vol. 66, 3

\begin{tabular}{|c|c|c|c|}
\hline 3DP Method & Technologies & Traditional materials & $\begin{array}{c}\text { Adapted for } \\
\text { pharmaceutical research }\end{array}$ \\
\hline \multirow{2}{*}{ Lamination } & $\begin{array}{c}\text { LOM } \\
\text { Laminated Object Manufacturing }\end{array}$ & Paper sheets & Not found \\
\hline & $\begin{array}{c}\text { UAM } \\
\text { Ultrasonic Additive Manufacturing }\end{array}$ & Metal sheets & Not found \\
\hline \multirow{2}{*}{$\begin{array}{l}\text { Directed Energy } \\
\text { Deposition }\end{array}$} & $\begin{array}{cl}\mathbf{E B F}^{\mathbf{3}} \\
\text { Electron Beam Freeform Fabrication }\end{array}$ & \multirow{2}{*}{$\begin{array}{l}\text { Metal wires or powders, } \\
\text { ceramic powders }\end{array}$} & Not found \\
\hline & $\begin{array}{c}\text { LENS } \\
\text { Laser Engineering Net Shape }\end{array}$ & & Not found \\
\hline
\end{tabular}

In light yellow are shown those adapted for pharmaceutical research [6,16,20,24,30,32,43,44,46,57,61,62,73,77,82,89,115]

${ }^{*}$ FDM and FFF refer to the same process, but FDM is trademarked by Stratasys, while FFF is not.

** SLA is the first 3D printing technology invented (1986), while CLIP is the most recent (2015) and the only one that is not a layer upon layer printing process.

Material extrusion, specifically FDM, is the method most widely used and is characterised by a pre-heated polymer filament or a semisolid being extruded through a nozzle in precise locations on a platform, using xyz positioning [73,82]. Once the first layer cools down, the following one is applied $[30,82,89,90]$. Depending on the shape of the printed product, a different material may be needed to provide structural support until the object cools down completely and solidifies, but afterwards it can be removed [73,115]. This support material can be considered waste, but with mindful planning and design, it can be reduced to a minimum or even eliminated altogether [115]. PAM technology is similar, except it uses non-melted, viscous materials [66].

Binder jetting selectively deposes liquid agents in order to bind layers of powder materials, without the use of a heat source $[82,89,108]$. Some binders may subsequently be removed, so the final product may not contain them [12].

Material jetting technologies imply selectively deposing micro-droplets of liquid materials at high speed [66]. For this reason, it is sometimes associated only with 2D ink-jet printing, but because the droplets can harden when exposed to light or when they dry or cool down, the material can be selectively deposited in successive layers $[12,30,89]$, therefore creating in the end a 3D object. A printhead can contain between 100 and 1000 nozzles [32].

Photopolymerisation uses vats filled with liquid photopolymers (resins) that are cured using a LED, UV or laser source $[30,82,89]$. With resolutions down to 0.2 micrometers, stereolithography is one of the most precise 3DP methods [6,46].

Powder bed fusion utilizes thermal energy (laser or electron beam source) to partially melt and bind layers of powder materials, a process called sintering [73]. Thermally activated chemical reactions may be used to bind together different types of powders or powders and gases [30,82,89].

Lamination is a process where sheets of material are overlaid and are bound together using either an adhesive, either ultrasonic welding [49,108]. Each layer is individually laser-cut to shape before the following one is added [30,40,49,73].

Directed energy deposition is a method that employs laser and electron beam thermal energy to melt and fuse solid materials [73,80,82].

Electrospinning is not itself a 3D printing process, yet it is used for research in conjunction with 3DP, traditional extrusion and molding [73].

Voxel printing is a more complex hybrid 3DP process where materials are deposited along electronic microcircuits or microfluidic channels [73]. The voxel is the $3 \mathrm{D}$ equivalent of the $2 \mathrm{D}$ pixel [84].

The common $3 \mathrm{D}$ printing process chain includes the following steps:

- Creation or adjustment of a CAD model, using specialised software, a 3D scan of an already existing object or medical imagery $[30,66,77,115]$. The CAD file describes the geometry and size of the $3 \mathrm{D}$ structure [32];

- Conversion to one of the printer-ready STL or AMF file formats $[30,73,115]$. These files describe the surface of the model in triangulated sections, depending on the surface curvature degree $[32,40,46]$. Increasing the number of the triangulated sections will increase the resolution of the printed piece [40];

- Slicing the 3D model into layers of specified thickness using specialist software that can also determine the amount and position of support material, which prevents the collapsing of the printed object $[46,66,73,76]$. The infill density of the printed object has to be specified as well - with $0 \%$ for a hollow structure and with $100 \%$ for a solid fill part [66];

- Transfer to and setting up of the files on the actual $3 \mathrm{D}$ printer $[30,115]$;

- Layer-by-layer manufacturing of the 3D product $[30,115]$;

Occasionally, drying or removal and discarding of support material and post-processing are required $[30,46,73,115]$. 


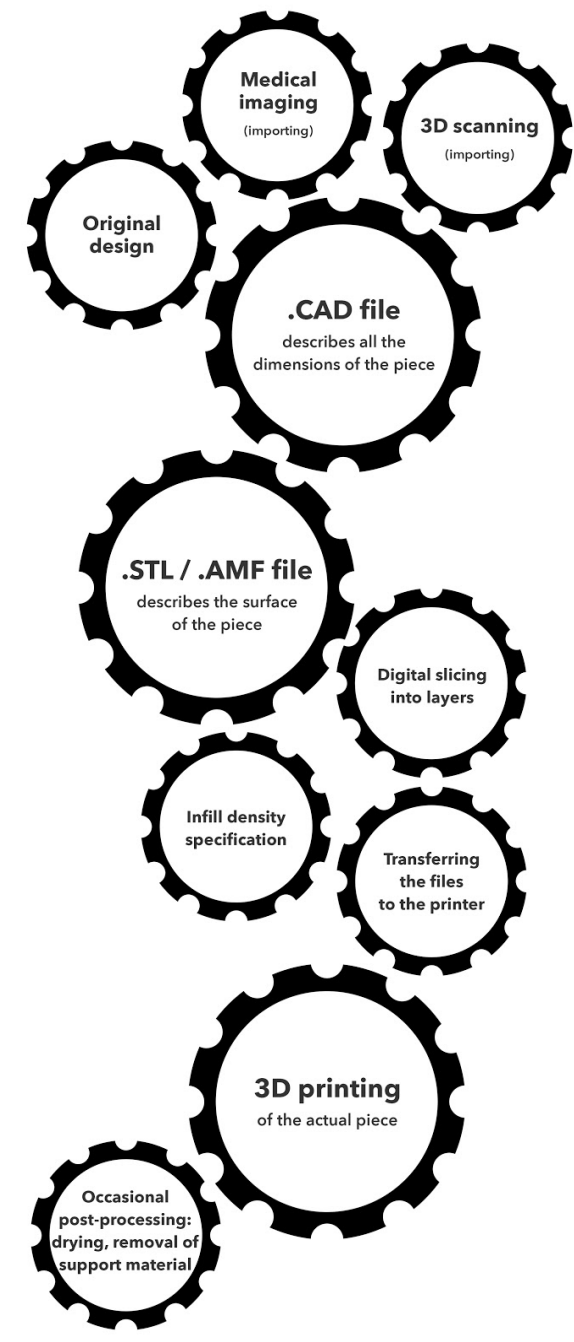

Figure 1. The additive manufacturing ( $3 \mathrm{D}$ printing) process PHARMACEUTICAL APPLICATIONS OF 3D PRINTING Apart from many applications unrelated to healthcare, $3 \mathrm{D}$ printing is currently used or under research for oral drugs, implantable drug delivery devices, tissue bioprinting, devices such as prosthesis and even food products $[6,24,73]$.

When compared to traditional drug manufacturing, it was observed that 3DP is capable of producing reasonably priced, on-demand, patient tailored drugs and/or an increased product complexity $[73,115]$.

The shapes and internal structures of current drug products are limited by current technologies. When using additive manufacturing, these characteristics can be as

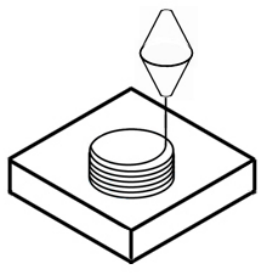

a

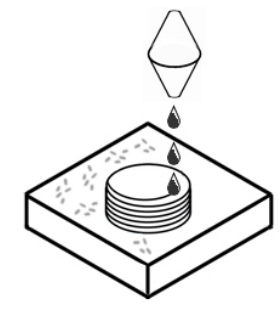

complex as one can imagine, and this could prove useful especially for multiple drug release profiles embedded in the same dosage form [62,77].

Some of the goals are minimising side effects, by achieving near-zero-order release by printing toroidal, cylindrical or perforated oral formulations or by using radial gradients of erosion or diffusion-controlling excipients $[65,73,83]$.

The ability to produce unique, individual or multi-drug and/or multi-dose formulations, can be the other important advantage of 3DP medicines, as demand for personalised medicine is increasing and becoming a megatrend, according to the FDA $[62,77,81]$.

Although research in the field started in the early 1990's, the FDA has approved only a single 3D printed orodispersible drug $\left(\right.$ Spritam $\left.^{B}\right)$ since 2015, but has shown great interest and engagement in the development of 3DP for pharmaceutical use ever since [62,46,77]. The Agency is involved in its own 3DP research and published a set of guidelines for 3D printed medical devices at the end of 2017, yet official guidelines for 3D printed drugs are still expected to be released [1,6,115]. Spritam $^{\circledR}$ tablets are manufactured applying a binder jetting method (Zipdose $^{\circledR}$ technology) using no compression $[46,73,108]$. While it was not developed for individual dosing, it solved another great issue: a higher dose was required (up to $1000 \mathrm{mg}$ of levetiracetam), but the addition of excipients made the traditional compressed tablet too large to be ingested by epileptic patients $[38,57]$. The 3D manufacturing process of Spritam $^{\circledR}$ substantially diminished the amount of excipients from the final product (down to $10 \%$ ) [77], thus reducing the overall size of the tablet and producing at the same time a throughout porous tablet [115], that is orally-disaggregating in seconds $[46,73]$ and which is bioequivalent to the conventionally manufactured immediate-release tablets $[2,32,108,115]$. The FDA documen-tation and the medication guide found on the company website clearly state the excipients list: "colloidal silicon dioxide, glycerin, mannitol, microcrystalline cellulose, polysorbate20, povidone, sucralose, butylated hydroxyanisole, natural and artificial spearmint flavor" $[1,2]$.

The 3DP methods that were adapted to handle pharmaceutical agents and biocompatible materials are: Extrusion printing (FDM), Binder jetting (BJ), Material jetting (MJ), Stereolithography (SLA), Selective laser sintering (SLS).
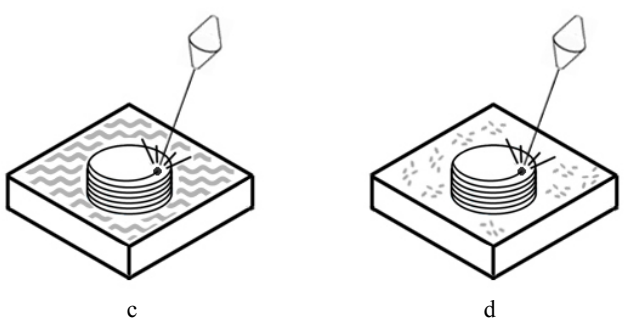

Figure 2. Simplified representation of the 3D printing methods applied in pharmaceutical research:

a. Melted solids (FDM) or gels (PAM) are extruded to form solid 3D products; b. Liquids can be used to bind layers of powder (BJ) or they can be deposited on different (solid) substrates (material jetting, DOD) to form 3D pieces; $\mathbf{c}$. Laser (SLA) or light (DLP) is used to photopolymerise liquids into 3D objects; d. Laser (SLS) is used to melt and bind layers of powder into 3D products. 
FARMACIA, 2018, Vol. 66, 3

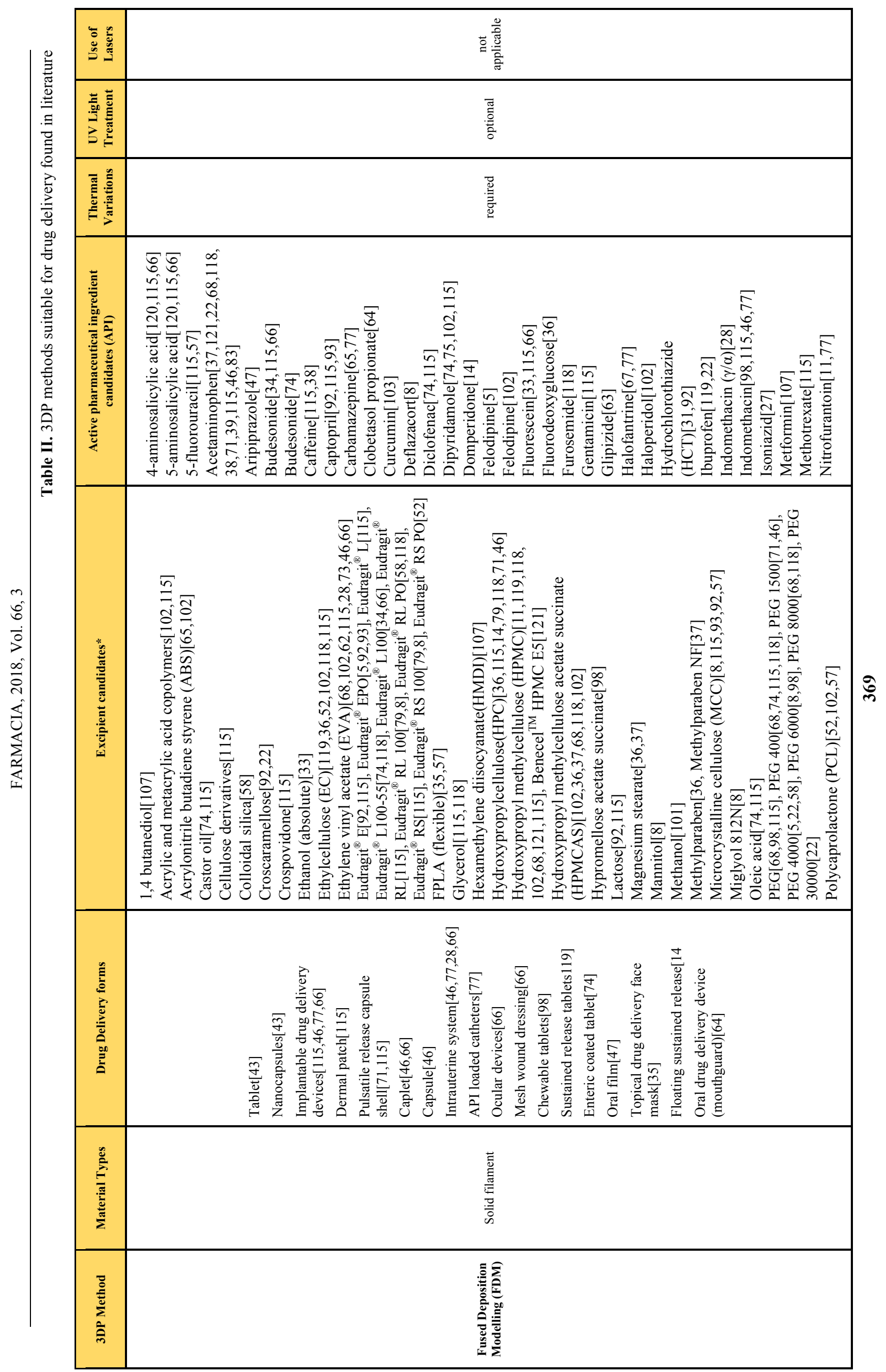


FARMACIA, 2018, Vol. 66, 3

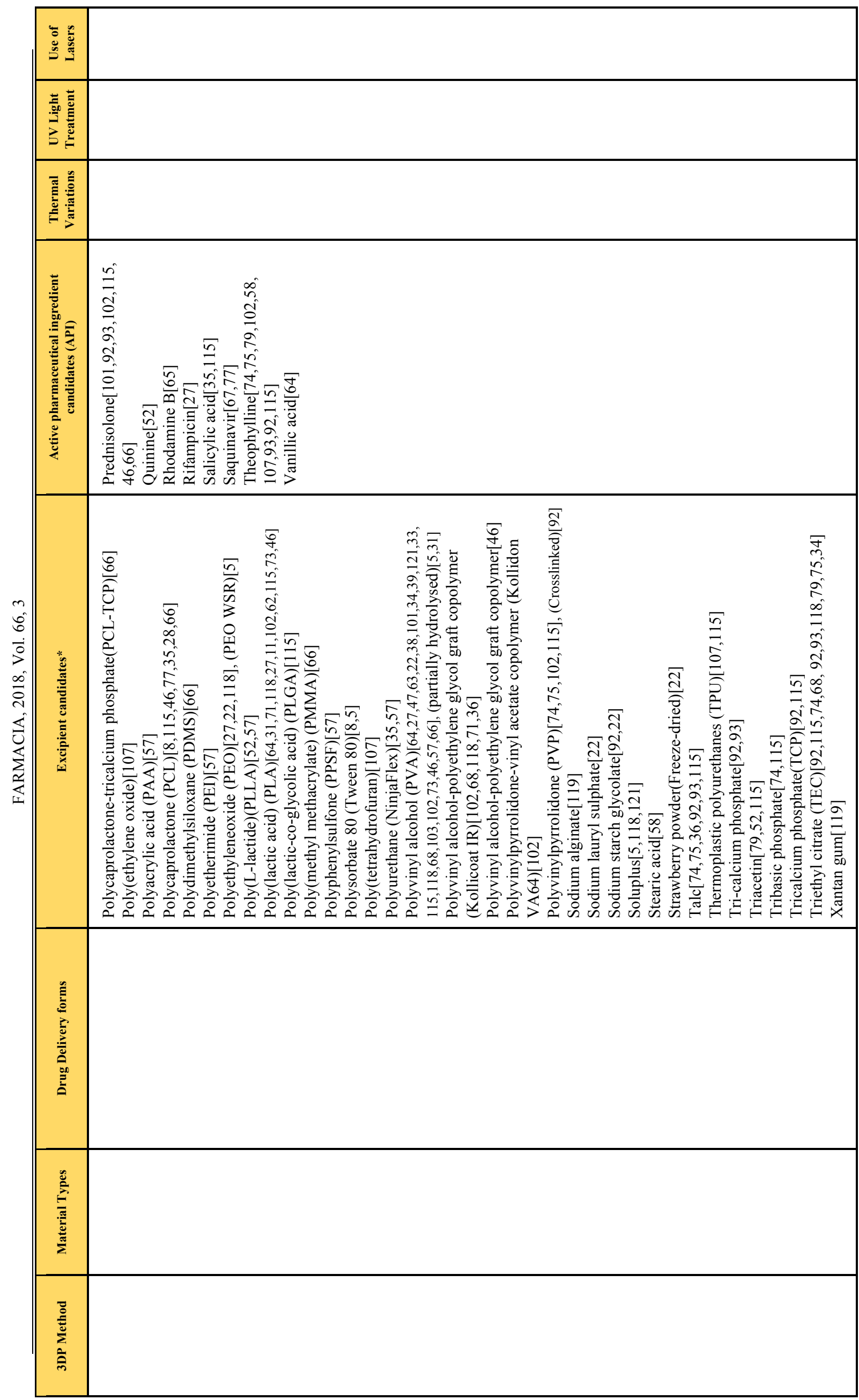


FARMACIA, 2018, Vol. 66, 3

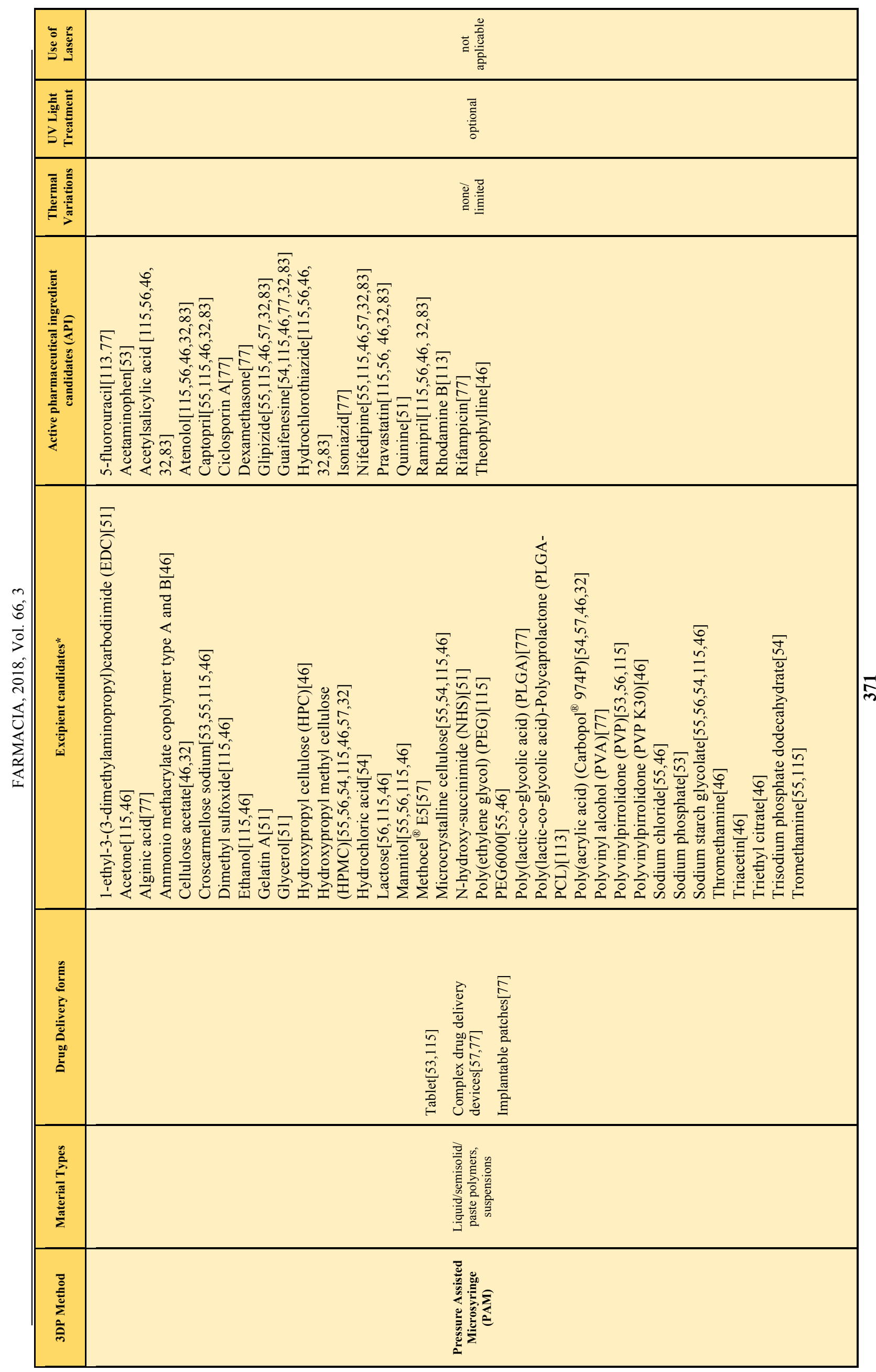


FARMACIA, 2018, Vol. 66, 3

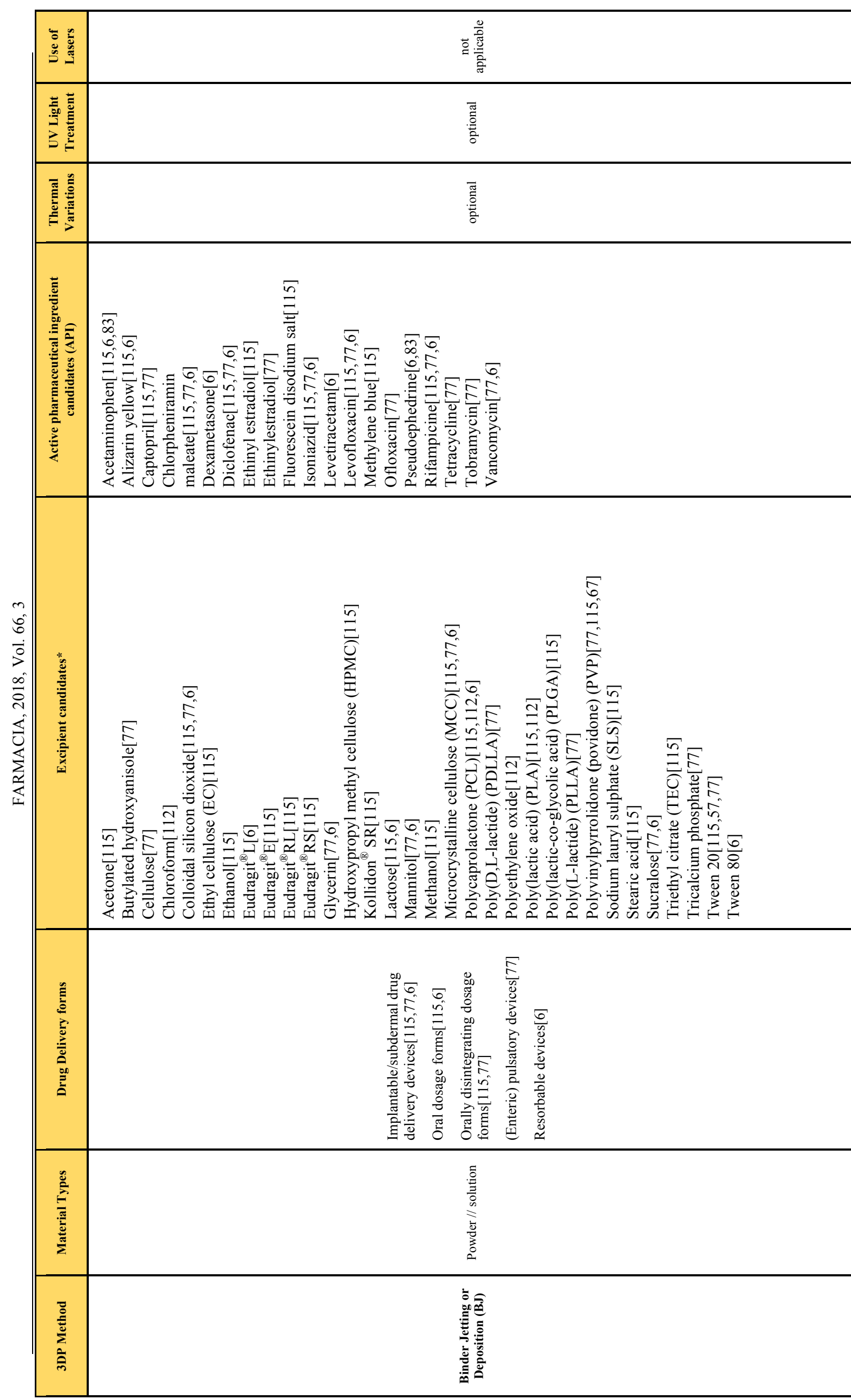

ํำ 
FARMACIA, 2018, Vol. 66, 3

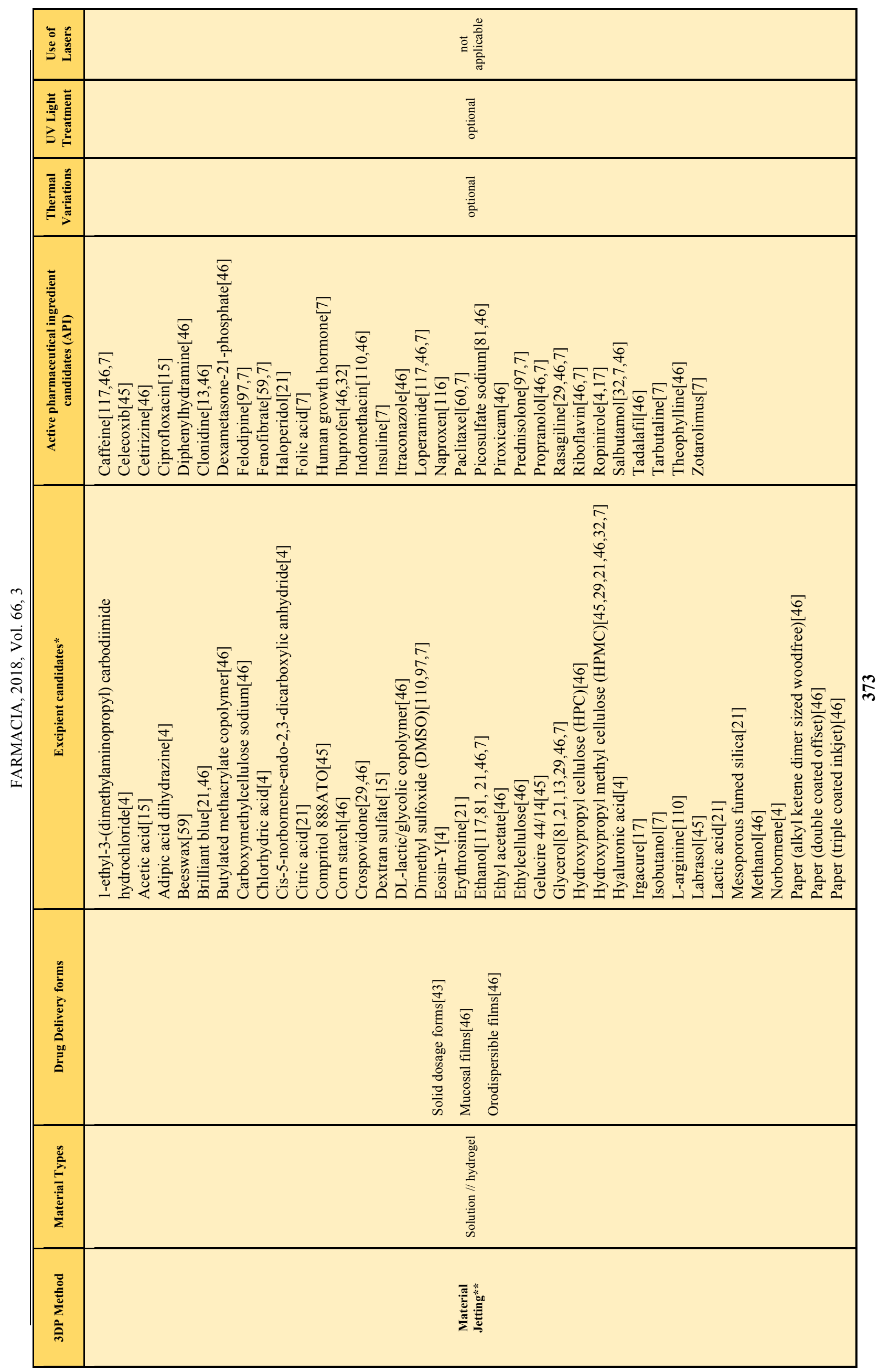


FARMACIA, 2018, Vol. 66, 3

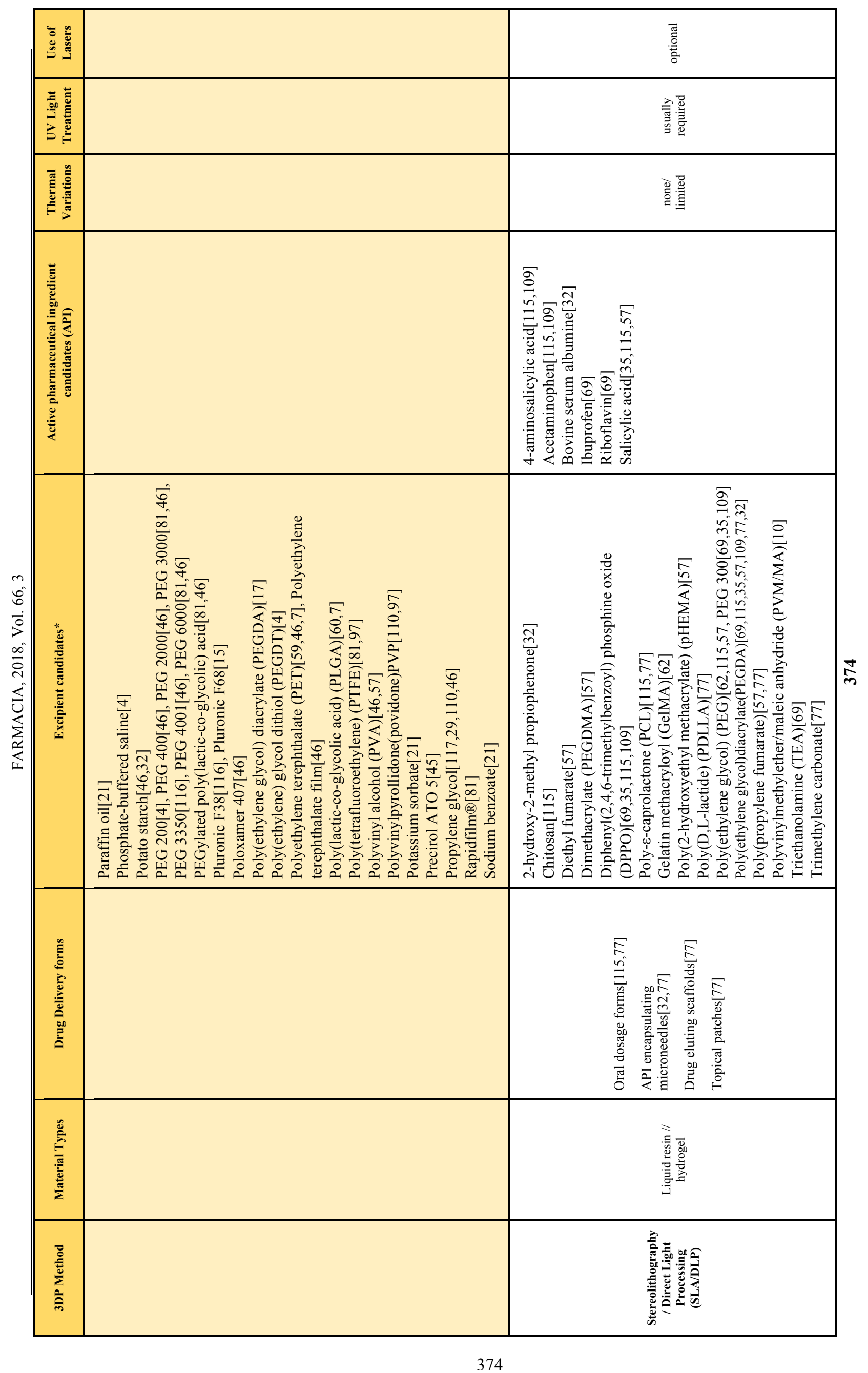


FARMACIA, 2018, Vol. 66, 3

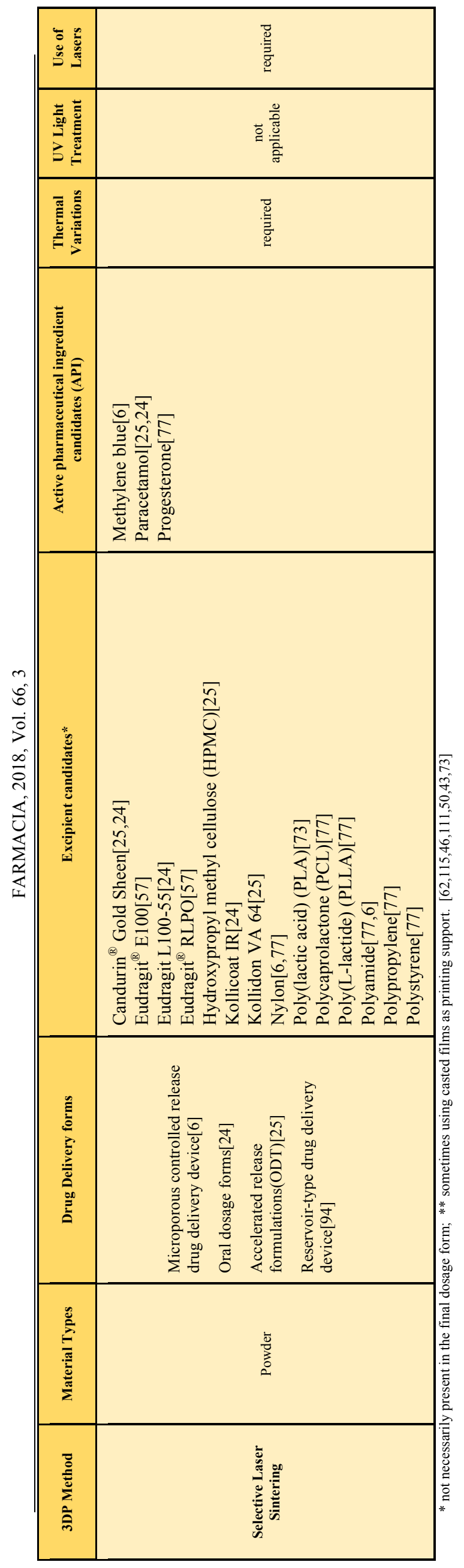




\section{Materials and Methods}

FDM and PAM extrusion printing methods make use of solid filaments, semi-solids or viscous liquids that may be heated to different degrees, pushed through one, up to three nozzles and deposited on a solid and sometimes heated platform, layer upon layer, a process that shows similarities to traditional pharmaceutical wet and hot-melt extrusion techniques $[20,46,62,66,73,115]$. The standard nozzle diameter is $0.4 \mathrm{~mm}$, but it can drop to $0.2 \mathrm{~mm}$ [46]. If the printed part has a complex shape, a different material has to be used through the second nozzle, in order to provide support for these overhanging segments until solidification is complete [77]. Several configurations are possible: either the platform is fixed and the nozzle moves in all three dimensions, either the platform moves horizontally and the nozzle vertically, either the platforms moves along all three axes [46,115]. The FDM solid filaments are produced by hot melt extrusion, yet no pharmaceutical-grade ones are approved for commercial use $[46,115]$. For the HME filaments, the transversal brittleness should be determined with a 3-point bend test, as well as the longitudinal stiffness degree with a tensile test [58].

The (internal) porosity of the printed piece can be digitally controlled by specifying the amount of material used for the infill scaffold structure, thus correlating with the drug release kinetics/profiles [66].

The printed object can be hollow and have a shelllike structure, either it can be partially or completely filled $[32,46,83]$.

Although the number of biocompatible materials is limited [43], some of the traditional FDM polymers were used in drug delivery research: poly(lactic acid) (PLA), ethylene-vinyl acetate (EVA) and polyvinyl alcohol (PVA), which are all non-toxic polymers [32,57,62,66,73,112].

PLA has been described as highly biocompatible and biodegradable and it is widely used for implants and nanoparticle formulations for drug delivery $[66,83,105]$. It is used for the manufacture of bioabsorbable/bioresorbable medical devices [23]. Yet, it is worth mentioning that due to its asymmetric carbon, racemic PLA, PDLA(Poly(Dlactic acid), PLLA (Poly(L-lactic acid) and PLGA co-polymer (poly(lactic-co-glycolic acids) have different characteristics [105], moreover some research calls for caution when using such implants [88]. PCL is another attractive candidate that is biodegradable and has a lower melting temperature of $60^{\circ} \mathrm{C}$, compared to PLA or PVA which both melt above $150^{\circ} \mathrm{C}$ [66]. Acrylonitrile butadiene styrene (ABS) has been shown to be biocompatible for several surgical applications, yet it is not bioresorbable, making it safe for passing out in the stool [65]. PVA was the first polymer employed for the production of medicines using FDM [24]. PVA has the attribute of swelling due to its hydrophilicity, and though this can be inhibited by the presence of certain salts, it is a property that can be exploited in controlled and sustained release drug delivery [32, 33]. PVA is already used as a binder, retardant or amorphous dispersion carrier in regular oral drug formulations [83]. The PLA and PVA polymeric matrices may generate unsought extended drug release patterns [93]. EVA is used extensively in transdermal delivery systems (TDDS) [96] and other drug delivery devices [28]. EVA is a biocompatible but not biodegradable polymer [28] and it is typically processed by regular hot-melt extrusion [96].

Thermoplasticity of the materials is essential for successful printing, yet most pharmaceutical grade polymers do not hold this property [5]. Besides the addition of plasticizers (HPC, Eudragit ${ }^{\circledR}$, etc.), some researchers proposed multiple polymer blends for increased thermoplasticity and dissolution enhancement, with better results for a certain Eudragit $^{\circledR}$ EPO, Tween 80, PEG 4000 and PEO WSR blend [5].

By soaking the unprinted filament for a significant time in a solvent based, saturated API solution, the drug can be passively diffused into the filament [6, $46,57,62,77,115]$. The solvent used for the API solution should be chosen in order not to dissolve or interact with the filament material $[32,66]$.

Different research showed that the ethanol soaked drug loaded filament did not exhibit any change in diameter, but, as expected, the drug loading was limited (to only $0.29 \%$ ), with uneven distribution towards the center of the filament [33,103], however, the printed tablets showed a homogenous redistribution of the active ingredient [33]. Higher drug loadings (1.9\%) are possible when using methanolic soaking solutions [101]. Depending on the infill degree, dissolution time varied between 6 and 20 hours, in a modified bicarbonate buffer [33]. In contrast, other research has proposed soaking the printed pieces (not the filament) in nanocapsules suspensions, resulting in possible higher drug content loadings [8]. Still, the low drug loadings coupled with the saturated API soaking solutions make this method quite cost inefficient [52].

For higher control and better dispersion of the drug content, the polymer can be melted together with the API, before it is manufactured into the filament using hot-melt extrusion, with drug loadings between 5 and $40 \%[62,75,77,115]$. The addition of plasticizers is usually required for higher drug loadings in order to preserve the properties of the filament $[32,107]$. However, higher drug loaded (up to $70 \%$ ) thermoplastic polyurethanes filaments were reported, with promising and mixed results [107]. The drug loading as well as the API particle size had an increased influence on the filament surface 
FARMACIA, 2018, Vol. 66, 3

smoothness $[27,107]$. With the exception of the low infill degree formulations, the content variation of all other printed tablets were within the limits of the USP standards [107]. The use of thermoplastic polyurethanes did not allow any burst effects, moreover they modulated the in vitro drug release [107].

Following dissolution testing for extended release tablets printed using two types of Eudragit ${ }^{\circledR}$ based HME filaments, between 11 and $85 \%$ of the API was released over a 2 hours time lapse (depending on the hydrophobicity of the plasticizers used), and between 50 and $100 \%$ of the API was released after 24 hours, while the polymer matrices were still intact at the end of the experiment [58]. The same authors describe an experiment for scaling up the hot melt extrusion process of the printable filament for industrial application [58].

The microstructure of PVA and PLA solid dosage forms manufactured using FDM, was investigated using high-resolution X-ray computed microtomography, and the results confirmed the consistency of the porous structure, but lacunar defects as well as excess material were also detected (more for PLA than for PVA); yet this cannot become the standard control method, as it is very time consuming [67]. The drug release of the same dosage forms was investigated using the basket method along with HPLC analysis and a delay was observed in comparison to a conventional capsule [67].

Other research analysed solid drug loaded PLA tablets using differential scanning calorimetry, thermogravimetric analysis, X-ray powder diffractometry, rheometrical instruments, friability tester, scanning electron microscopy and mercury porosimetry [93,38].

Drug or excipient loaded filaments were reportedly obtained by $\mathrm{HME}$ at $100^{\circ} \mathrm{C}$ with varying results: Eudragit $^{\circledR}$ EPO only filament was printable, but the printed piece was deformable; lactose and microcrystalline cellulose loaded filament showed discontinuous flow through the printer nozzle; also, different ratios of Eudragit ${ }^{\circledR}$ EPO, triethyl citrate and tricalcium phosphate filaments were analysed [93]. Different APIs were introduced in the filament formulation and showed an insignificant plasticizing effect at $12.5 \%$ concentration and were successfully printed [93]. Captopril showed increased degradation $(22 \%)$, most probably due to the longer time needed during the HME manufacture of the filament, rather than the few seconds in the heated printer nozzle [93].

A hot melt extruder can be coupled with an FDM printer in order to use extemporaneous filament preparation for immediate printer use [83]. For bioprinting, the filament may be eliminated altogether, as powder or pellets could be run through a hot melt extruder that extrudes the material right into the printing nozzle (Precision extrusion deposition) [83].

FDM was employed to produce pediatric chewable tablets with excellent taste masking properties, using HME in-house fabricated filament [98].

Other researchers argue that accelerating the drug release was the trend of the last decade, therefore proposed 3DP tablets with longitudinal or transverse perforated lattice structures that would expedite drug release as well as allow sinking into liquid media, in contrast to low infill printed tablets that usually float [92].

Different ratios of HPMC AS MG, HPMC HME, Kollicoat and Kollidon, along haloperidol were used to produce HME filaments, of which the HPMC HME, Kollidon and haloperidol blend had optimum FDM printability [102]. The study also compared the drug release of the unprinted filament to the release of different infill printed tablets [102].

Commercial PVA filament was cut and milled before blending with glipizide, then re-extruded using HME, and afterwards printed using an FDM printer into controlled release tablet-in-tablet formulation, with a maximum drug loading below $5 \%[63]$.

In another study, due to the alternation between the two nozzles of an FDM printer that used two types of filaments to produce enteric coated tablets, frequent blockages were encountered but were overcome with the addition of lubricants, resulting in a two-phase drug release pattern and a complete dissolution of the polymer, but with significantly longer disintegration times in contrast to pharmacopoeial standards [74]. In order to insure similar $\mathrm{pH}$ protection, it was observed that a thicker enteric coating was necessary for the printed tablets in comparison to regular gastro-resistant caplets [74]. Also, in one of the formulations, tribasic phosphate sodium reacted with theophylline, which was degraded to a great extent [74].

The attempt to use FDM to print aripiprazole orodispersible film was demanding, but successful, with better dissolution rates for the printed film when compared to the casted one [47].

In vitro and in vivo research describe the pairing of rifampicin and isoniazid in a modified release dual compartment dosage unit (with a drug loading above $60 \%$ ), in order to avoid the interaction resulted from their simultaneous gastric release [27]. Production implied the use of FDM and HME [27]. The retardation was much more pronounced in the in vitro studies compared to the in vivo ones, suggesting optimisation of the sealing design is necessary [27].

A study on a hydrochlorothiazide controlled release tablet also used multiple nozzle FDM and different polymers in order to modulate the drug release, attaining in vitro zero order release kinetics [31].

An in vivo behaviour investigation of four different FDM capsular devices (subsequently filled with a 
radiopharmaceutical tracer) was performed in rats, with the help of microPET/CT imaging and concluded that 3DP could be used to accelerate preclinical animal studies in the future [36].

The FDM production of enteric uncoated tablets highlighted how the use of plasticizer and lubricant could modulate the extrusion temperatures [37]. The 5 or $50 \%$ drug loadings influenced whether the API was in amorphous or crystalline form [37].

FDM was also proposed for the production of paracetamol and ibuprofen orodispersible films with multiple layers, some of which had taste masking properties, containing PEO and freeze-dried strawberry powder [22], although it is not clear how the taste masking would persist as soon as the oral disintegration sets in.

The combination of soluble, swellable and gastroresistant polymers was proposed for the manufacture of a multi-compartment capsular device, using reextruded, commercially available PVA and EVA fillaments [68].

A domperidone, floating, intragastric sustained release device was printed with the aim of achieving better solubility in acidic conditions and in vivo testing in rabbits showed an $8 \mathrm{~h}$ gastric residence time [14], while other research used the same HPC and its slow-eroding properties to print a pulsatile drug device [71].

The percentage of HPMC added to the polymer blend, influenced the porosity of the printed pieces, thus modifying the drug release over a period of 24 days [11].

API degradation may be more aggressive during the HME of the filament, rather than the FDM printing process [93]. Even if the HME working temperature was lower than the FDM printing temperature, the longer period of time the drug was exposed to heat during HME appears to be the foremost detriment [93].

A study in which a linear release carbamazepine perforated drug container was printed, aiming for the reduction of the frequent side effects, resulting in improved patient compliance, also concluded that the hole diameter (rather than the number of the container perforations) was better correlated with the release rate [65].

A different study used an enteric polymer to coat 3D printed tablets and then compared the drug release with two other commercially available drugs, showing improved sustained release [34].

The effect of geometry on the drug release was studied for a variety of cube, pyramid, cylinder, sphere and torus printed products, with large variations of the time needed for $90 \%$ API release $\left(t_{90}\right)$ for similar surface area products, from $2 \mathrm{~h}$ in the case of the pyramid to $12 \mathrm{~h}$ in the case of the sphere or cylinder [39]. The shape may also impact on the transit time in the case of expandable oral drug delivery systems, with a tetrahedron showing the most extended gastric residence time when compared to other shapes [39].

One study showed that the percentage of API released in vitro for certain polymeric $3 \mathrm{D}$ printed tablets, was almost complete for lower doses and smaller sizes, while for larger doses and sizes, the percentage barely passed 50\% [79].

Solvent dissolution of three distinct polymer filaments, followed by the addition of API was recently performed (solvent casting technique), resulting in a drug-loaded film that was extruded into a new filament, thus insuring an even distribution throughout the extruded filament and bypassing the otherwise higher thermal values needed for melting the polymer filaments and API [52]. The in vitro dissolution tests (some of which lasted for 6 months) of the printed implants, resulted in quite different amounts of drug released within the same time frame (sometimes more than 20 fold), depending on the polymer employed, with PCL and PLLA exhibiting the fastest release and Eudragit ${ }^{\circledR}$ RS and EC the slowest [52].

Individualised oral sustained delivery devices, in the form of mouthguards, were printed and tested in a first-in-human study, using 3D digital files obtained via an intraoral scanner [64].

With PAM technology, viscous material is extruded at room temperature, using mechanical extrusion or a pressurized piston $[32,57,77]$ and is mainly used for tissue scaffolding and complex drug delivery devices [57,77].

Crosslinking polymers are preferred either to avoid drying time that otherwise would be needed, either to increase the mechanical strength of the printed form [77].

Two different examples of polypills created using PAM extrusion, focuses on the treatment of hypertension associated to diabetes, with first formulation containing pravastatin, atenolol, and ramipril in three separate compartments with different release profiles and another separate compartment holding acetylsalicylic acid and hydrochlorothiazide for immediate release, while a second formulation contained captopril, nifedipine and glipizide $[55,56,57,77,92]$. The compartments of these two polypills were either for immediate release, extended/sustained release or an osmotic pump (with zero-order drug release) [55,56]. Previously, a bilayer tablet with a high drug loading (for immediate and sustained release) was printed using PAM [54].

Paracetamol was chosen as representative for APIs that hold limited direct compression characteristics, and PAM was used to obtain $3 \mathrm{D}$ printed immediate release tablets with up to $80 \%$ drug load, and no physical or chemical changes were recorded for the printed API [53].

PAM was used to print drug-loaded implants for short-term release for ear-nose-throat and genital application, with researchers focusing on drug 
FARMACIA, 2018, Vol. 66, 3

degradation, swelling and different crosslinking methods efficiency of glycerol gelatin that were evaluated after the custom modification of the $3 \mathrm{D}$ printer deposition cannulas and of the sliced g-code files [51].

In vivo testing has been performed on athymic, pancreatic tumor-bearing mice for an implantable, biodegradable, 5-fluorouracil sustained release patch, that was printed using hot PAM and which significantly reduced the tumor size when compared to the control [113].

Hydrogels can be used in extrusion and ink-jet printing. They are of special interest in drug delivery research, especially on account of their porosity and high diffusion rates, with the activity of some hydrogels being conditioned by $\mathrm{pH}$ or enzymatic presence, thus lending itself to controlled drug release [62]. Natural hydrogels under current research in $3 \mathrm{D}$ printing include: agarose, alginate, chitosan, gelatin and fibrin [62]. The API can be diffused from a saturated solution into the hydrogel or simply pre-mixed in [62].

Binder jetting (BJ): a platform is covered with a layer of the API powder (mixed with excipients or by its own), then a liquid bonding agent is spotted in predefined locations onto the powder layer, followed by another layer of the API spread by a roller, then another deposition of binding agent and so on [62, 73,115 ,]. The binding solution can act in different manners: it can either dissolve a fraction of the powder layer it is deposited on, evaporates and recrystalizes, thus solidifying the layers together, either a localised polymerisation reaction may occur between the binder and the powder layer $[19,62,73]$. Conversely, the API can also be contained into the binding solution or suspension and the powder can act as the excipient, especially when the drug loading of the printed form is minimal $[62,115,77,19]$. Of course, for maximum drug loading printed forms, one or multiple APIs could be included both in the powder bed, as well as in the binder solution [77]. This 3DP process is similar to wet granulation due to the fact that drying at room temperature or applied heat may be required in order to remove any residual volatile solvents, which may as well affect the polymorphism of the API [32, 73,115]. Smaller powder particle size is the determining factor for a better resolution of the printed product, but special consideration has to be given to size related flowability and cohesion issues [115]. The ink stream can either be a continuous flow, either be divided into droplets using a piezoelectric crystal print head $[57,65]$. With low or absent thermal variations, this method can be employed for thermolabile APIs [77]. Volatile liquids and thermolabile substances cannot be used with thermal heads, which can heat up to $300^{\circ} \mathrm{C}$ [57].
Reported diameter of droplets ranges between 10 and 80 micrometers, while powder particle sizes can vary between 45 and 150 micrometers [57,112].

The choice of excipients is paramount when considering implanting a DDD in the form of a bone graft: using tricalcium phosphate (TCP) for example, results not only in a porous structure that insures an elevated drug release rate, but could also annul the necessity of a subsequent extraction surgery [26,77]. Most of the products made using powder binding 3D printing are marked by a high porosity, which could either be a sought-for attribute, as in the case of Spritam ${ }^{\circledR}$ orally disintegrating tablets, yet it could prove to be an impediment in the handling of the products, due to increased friability [115].

Material jetting: defined diameter droplets are ejected through a thermal or piezoelectric print head and accurately placed onto a substrate that is not necessarily in powder form or even not necessary present at all, as the droplets can solidify in a stalagmitic manner [7,17,46,62,73]. However, consecutive attempts to print on the same substrate surface resulted sometimes in unexpected doses, probably due to the contact between the printer head and the substrate or previous printed layers [7]. If thermal energy is applied, the temperature and pressure will increase in the print head and it will determine the droplet discharge through the nozzle due to the formation of a superheated vapour bubble, hence the alternative name of this technique: bubble jet printing $[7,32,62]$. Thermal printheads cannot be used for volatile liquids [32]. If piezoelectric crystal actuation is used, the shape of the lead zirconate titanate crystal is rapidly and reversibly deformed by an electric current, determining the apparition of sound waves that cause the droplet discharge through the nozzle $[7,32,62]$. Piezoelectric actuation is not a heat generating process [83]. A third type of 3D inkjet printing uses a group of individually controlled, pressure regulated microvalves, capable of depositing droplets of the same material or different ones [62]. Inkjet droplet diameter may vary between 10-100 micrometers and its volume between 1-300 picoliters [32,73,97]. This method usually results in drug loadings ranging in the micrograms domain [6].

Particle size, viscosity and surface tension are some of the factors that influence flowability through the print head $[6,32,95]$. Suitable viscosities and surface tensions of the drug inks must be paired in order to obtain spherical droplets [7].

The physical properties of fluids used in commercial inkjet printing have been determined and are available for guidance in drug delivery research [83]. The ink viscosity can vary between 2-100 $\mathrm{mPa} \cdot \mathrm{s}$, depending on the type of inkjet technology, with typical values around $10 \mathrm{mPa} \cdot \mathrm{s}[19,83]$, while surface tension should situate around $30 \mathrm{mN} \cdot \mathrm{m}^{-1}[19]$. 
Water viscosity is only $1 \mathrm{mPa} \cdot \mathrm{s}$ and surface tension is $72 \mathrm{mN} \cdot \mathrm{m}^{-1}$, so pure aqueous solutions are not a suitable API ink [19]. The addition of surfactants is necessary, while the addition of glycols can increase viscosity and decelerate ink evaporation, yet some glycols are incompatible with different APIs or exhibit certain side effects $[7,19]$.

The nature of the substrate may influence API polymorphism, subsequent the solvent evaporation after printing [7].

Solvent casted or hot-melt extruded, excipient-only films can be used as printing support and DOD could be used for the deposition of precise doses of one or more APIs [95].

Using a film substrate on which a single, continuous layer of liquid or suspension is deposited is sometimes considered 2D $[46,86]$ because the support film is already manufactured (casted), but the current review will consider this process as a hybrid additive manufacturing method, as successive layers can be superposed on the same surface, but also because inkjet printing can be used not just on plane surfaces, but on irregular (3D) surfaces as well $[6,9,10,29]$. The support materials can also include prefabricated excipientonly tablets or oral wafers [7,33]. The amount of jetted ink and most specifically longer drying times, may influence crystallization, that could be inhibited using povidone [97].

Several researchers have presented formulations containing high concentrations of ethanol (some up to $95 \% \mathrm{v} / \mathrm{v}$ ), yet "FDA guidelines stipulate that medicines should not produce a blood concentration of more than $25 \mathrm{mg} / 100 \mathrm{ml}$ of ethanol, and over-the counter preparations of ethanol cannot contain more that $5 \% \mathrm{v} / \mathrm{v}$ ethanol" [7].

Inkjet printing could easily employ coloured API solutions to print visible unique patterns (geometric designs, barcodes or text) that could help identify a specific formulation [85].

The resolution of inkjet printing was put to the test in a study that introduced the printing of a drug within a visible QR code (Quick Response Code) on an flexible, porous orodispersible substrate, that would help identify the API, dose or any other information embedded in itself that may improve safety or prevent counterfeiting, as a smartphone with a QR scanner application could be used [21].

Specific geometries of 3D printed solvent-free, beeswax based, solid dosage forms were proposed in order to investigate the manipulation and prediction of drug release models [59]. Interestingly, the beeswax surface efflorescence phenomenon could prove its utility for the limitation of an undesired burst release of the API [59].

Three different types of commercially available, pharmaceutical-grade films have been used for printing a drug loaded ink, with results varying according to hydrophobicity, porosity, topography and coating of the film surfaces [81].

Thermal inkjet printing was used to produce orodispersible films and they were compared to casted films, with overall better results for the printed ones, but especially in dose variation, brittleness and drug crystallization [13]. Printing smaller droplets may result in the formation of crystals so small, that they may not influence the mechanical properties of the film and even appear amorphous when tested [13].

Taste masking of bitter APIs was successfully obtained for jet dispensed oral films [99], a technique that could be applied in inkjet printing.

Bone implants coated with antibacterial formulation using inkjet printing were also reported [85].

Inkjet printing was used to apply uniform coatings of insulin and polymer ink or anti-cancerous formulations on metallic microneedles, resulting in rapid release profiles [20].

Drug loaded polymer, well-defined micro shapes were printed on glass plates, from which they were easily detachable [60].

Inks may include amino acids, which were determined to be favorable for the stability and dissolution rates of certain poorly soluble APIs [110].

Direct printing of hydrogel precursor ink was performed on precompressed tablets, with subsequent light exposure induced photopolymerization [4].

DOD inkjet printing can also be used to obtain monodisperse particles such as drug encapsulated microspheres, with increased uniformity and particle size control when compared to regular manufacturing [83]. Similarly, the printed droplets can be freeze-dried using liquid nitrogen [19,33].

A hybrid UV inkjet method was used to print a solvent-free, drug-loaded ink on a poly(ethylene terephtalate) film, that was cured with UV light during and post printing [17].

Stereolithography (SLA) and Direct Light Processing (DLP) use photo-polymerization in order to form solid parts, when layers of photosensitive material in which the API is dissolved are cured, then solidified using a UV laser or a light projector $[24,62,73,115]$. Though the majority of resins usually employed in this method are toxic or carcinogenic, thus not suitable for pharmaceutical application, photopolymerizable hydrogels are the ones currently researched on $[24,46,73]$.

There are two different configurations: the first one places the laser source underneath the hydrogel tank, with the platform that the part is being printed on, constantly moving upwards; the second configuration has the building platform inside the 
tank of gel or resin, constantly moving downwards, sinking into the liquid as the laser cures each layer of material from above the tank [20,115]. The platform advances upwards or downwards for an interval that is corresponding to the thickness of each printed layer [32].

The resolution of the SLA printed product is highly elevated (up to 20 micrometers), as is the printing speed $[24,77,109]$, but the risk of contaminating the pool of API hydrogel is significantly higher when compared to other methods $[46,62]$.

UV light post-curing is regularly used in order to increase the robustness of the printed piece and this step is considered as a weakness for pharmaceutical applications [46,115].

Stereolithography produces none or limited heat, so it is one of the 3DP methods that could safely process thermolabile compounds [24,115].

SLA has been used for tissue bioprinting, surgical implants and microparticles $[69,77]$.

Products for external use were also researched on: following the 3D scanning of a patient's face, an anatomical identical, but hollow nose mask, loaded with salicylic acid for acne treatment, was printed using SLA with best results and FDM (with poorer results: accentuated brittleness and/or drug degradation) $[35,57]$.

Traditional materials like epoxy or acrylate monomers are not biocompatible, but other polymers may be suitable candidates: chitosan, PEG, PCL, poly(propylene fumarate), trimethylene carbonate, PDLLA and others [62,77,115].

Drug loaded, pre-wetted hydrogels were printed using stereolithography with mixed results, depending on the API, the excipients and the water content [69].

DLP photopolymerisation was also employed for fabricating long term drug delivery microneedles ( 5 weeks controlled release) embedded with decarbazine for skin cancer treatment [20].

Although toxic components were used in one research paper, the model used stands for a proof of concept that demonstrated very low API degradation and high, almost total drug release rates from the SLA printed tablets [109].

Micromolds were printed using SLA and were subsequently used to fabricate microneedles, which were then coated with different active ingredients using piezoelectric inkjet printing $[9,10]$. The microneedle triangular base had equal 150 micrometers sides, while the microneedles themselves were 500 micrometers tall [10].

Microneedles obtained through DLP stereolithography, coated with antimicrobial agents, were also reported for possible application in wound dressing [20].

Selective laser sintering (SLS) uses layers of powder material similarly to binder jetting, but instead of binding liquids it employs localised laser thermal energy in order to melt parts of each powder layer and then bind them together $[62,73]$. Due to the high heat applied by the laser, but also due to the elevated heat that the powder bed may be maintained all along the printing process, the best suited powders are semi-crystalline polymers [62]. Moreover, high-melting point powders can be alternated sequentially with low-melting point powders and only the latter may be sintered and act as a binder for the high-melting point powder layers [73].

The powder containing the APIs and excipients needs to include at least one component that absorbs the laser energy at the operational wavelength in order for sintering to occur [24,25].

SLS common materials are powder metals, but for pharmaceutical applications PLA, Eudragit ${ }^{\circledR}$, polyamide, nylon and other elastomers could be employed, most of them for manufacturing porous, controlled-release drug delivery devices [57,73,77]. Due to the high temperature generated, sensitive APIs would easily be degraded, therefore the delivery device is sometimes sintered separately and the API is incorporated post printing [24].

Still, research shows that when sintering was employed at $80,90,110$ and $135^{\circ} \mathrm{C}$, degradation of the chosen API (paracetamol) was practically absent, though part of the API transformed from amorphous to crystalline state [24,25].

Reservoir drug delivery devices (with zero-order release kinetics) were printed using SLS, either with a polymer based reservoir shell, either with a polymer and API shell, both filled with API in the core [94].

However, sintering at different speeds the same blend of API and excipients, resulted in mass variation of the printed tablets, as well as the dissolution profiles [25].

SLS drug research is limited also as a consequence of the restrictive costs of equipment [77].

Pen based 3D printing/writing is a hybrid inkjettype device that could be hand-held and maneuvered during surgery in order to build $3 \mathrm{D}$ structures inside the patient's body [73].

Devices manufactured from shape memory polymers (SMP) are usually referred to as printed in $4 \mathrm{D}$ (four dimensions), as they can timely alter their shape and drug release potential after implantation or ingestion when differences in $\mathrm{pH}$ or temperature occur or when they are stimulated by light exposure, by applied pressure or by indirect heating in a magnetic field [62,111]. Biodegradable SMPs for controlled and sustained drug release include: copolyester urethane, oligo[(rac-lactide)co-glycolide]tetroles [111], poly( $\varepsilon$-caprolactone) (PCL)/trisilanolphenyl polyhedral oligomeric silsequioxane(TspPOSS) [50]. 


\section{General advantages that apply to most 3D printing methods}

Manual dose fractionation/splitting of regular oral drugs is sometimes difficult due to size or shape, it may also increase the risk of potential errors, or it may compromise the API as in the case of enteric coated or complex dosage forms, when drug release will be altered $[6,7,32,74,106]$,

One of the most important benefits of $3 \mathrm{D}$ printing is facilitating dose personalisation (especially for APIs with narrow therapeutic indices) and therefore supplying a patient tailored treatment, especially for pediatric, geriatric use or paired with particular metabolic rates or genomic information $[32,33$, $73,115]$.

In practice, liquid dosage forms are ideal for patients experiencing dysphagia, for pediatric patients (even newborns), for geriatric or impaired patients and also in antipsychotic treatment, but when those are not available, orally disintegrating tablets and films are most suitable $[6,7,46,47,86]$. The possibility of creating such formulations using 3DP, coupled with the advantage of personalising the drug product according to the child's weight, disease severity and his preferences on shape or colour, could better assure treatment success $[6,73,86]$.

The dosing can be modified either by altering the overall size of the finished product, either by choosing a different filling ratio of same-size shelllike products $[46,77]$.

This versatile personalisation and reproducibility should ensure higher efficacy and safety of the drug therapy, with less side effects, especially for APIs with a narrow therapeutic index $[46,57,77,106$, 107,108].

3D printing could be suited for use in hospitals, mobile military facilities and for low stability drugs $[62,73]$.

3DP can prove quite useful in preparing dosage forms for clinical trials, especially when we consider the 800 -fold range of doses required in first-inhuman trials $[106,115]$, but it could also accelerate pre-clinical animal studies [36].

Dissolution of poorly soluble APIs is improved, as a result of the potential amorphous APIs forming during printing $[32,46]$.

Disintegration and dissolution rates can be increased either by printing hollowed or highly porous structures, thus increasing the contact surface area, either using 3DP extrusion methods resulting in amorphous dispersions or even filling inner cavities with loose powders [6,73]. For an expedited API release, the infill of the printed form can be unbound, loose powder, thus assuring maximum disintegration and dissolution speed $[6,77]$.
Using one or multiple nozzles, a single tablet could be printed, coupling multiple APIs in a single blend or in different, accurately distributed layers or compartments, with different release profiles, resulting in improved adherence and efficacy for polymedicated patients $[6,46,56,57,106,115]$.

Contrary to compressed powder tablets, the actual location of the API within the 3D printed dosage form can be precisely designated [6]. The 3D printed pieces can have any geometry [89].

$3 \mathrm{D}$ printing can produce drugs with a considerable smaller size when compared to traditional compounding industrial machines [115].

Certain excipients could be limited or excluded from the formulation in certain intolerances (lactose, sucrose) [115].

Manufacture could be on demand, and the need for long-term storage of finished products can be eliminated [115,108].

Extremely low quantities of API can be printed, even as low as 3ng of API [73].

When considering smaller batches, $3 \mathrm{D}$ printing is less expensive than traditional industrial manufacturing [86].

Low stability APIs could be printed for immediate administration, while different research proposes associating simple API synthesis with 3DP [73].

Also, it is easier and far less expensive to edit and modify the CAD digital files, rather than modifying or replacing industrial equipment [73].

\section{General drawbacks}

Appropriate materials are still limited for drug 3D printing [6].

Regular control and maintenance of nozzles and print heads is necessary, to insure clogging or drying up doesn't install [6].

Post processing including drying using hot air, microwaves or infrared sources may be needed in some instances, when residual solvents need to be removed from the final product $[6,57,70]$.

Different printing defects can appear either due to the vibration of the printing plate (banding), either due to the swift thermal variations (warping), or even the collapse of the inner structure [73].

When considering polypills, limitations occur especially when taking into account the number of APIs used and the size of the final product [46, 73,106].

Air safety should be monitored inside the manufacturing facilities for possible pollutants: ultrafine particles resulting from the processing of PLA and ABS filaments, fine powders, organic solvents and other unknown heat related degradation compounds [115]. 
FARMACIA, 2018, Vol. 66, 3

Table III. Advantages and drawbacks of specific 3D printing methods

Fused Deposition Modeling (FDM)

\begin{tabular}{|l|l|}
\hline Advantages & Drawbacks \\
\hline
\end{tabular}

Because FDM is less expensive, easier to operate and there are a large number of producers, this is now the most widely used 3DP technology $[6,24,66]$. No use of solvents, improved sturdiness when compared to powder based 3DP methods, an almost limitless number of geometrical configurations [20,115].

High drug uniformity [6].

The same bulk filament can be used for the preparation of different doses and/or release rates, simply by choosing different infill percentages [107]. Poorly soluble APIs can be formulated into amorphous solid dispersion filaments [83].

The high temperatures may generate amorphous forms, which may prove desirable for poorly soluble APIs [32]. The high temperatures could inhibit microbial growth [115].

Surface imperfections may appear [6]. Warping and shrinking of the printed object especially if platform is not thermostated or if the printing chamber is open, allowing the printed object to cool down too suddenly $[32,46]$.

Prerequisite filament formulation is necessary, as no pharmaceutical grade commercial ones are available $[6,58]$.

Limited number of suitable polymers [102].

Temperatures required for melting the drug-loaded filament may exceed $120^{\circ} \mathrm{C}$ and are inconvenient for thermolabile APIs or excipients [6,24,66,73,77].

Breaking up of the filament [115].

Distortion of the filament around the extrusion feeding gears or failure to grip and advance the filament may appear, if it doesn't have a consistent diameter [107,115].

Most printed pieces are anisotropic [89].

Slow printing speed [73]. Typically $40 \mathrm{~mm} / \mathrm{s}$, up to $150 \mathrm{~mm} / \mathrm{s}[32,46]$.

May encounter difficulty in removing and reusing support materials employed for complex structures $[66,73,77]$.

The impregnation of API into the filament is time consuming and the API is not distributed homogeneously inside the filament [66,77]. The API will diffuse even less into the filament if it is highly soluble into the impregnation liquid [77].

\section{Pressure assisted microsyringe (PAM)}

\begin{tabular}{|l|l|}
\hline Advantages & Drawbacks \\
\hline $\begin{array}{l}\text { Room temperature operation [6,57] } \\
\text { High drug loading [6]. }\end{array}$ & $\begin{array}{l}\text { Use of toxic solvents [32,57] } \\
\text { Post-printing drying of the printed piece may be necessary and incidental shrinking may alter its } \\
\text { physicochemical properties [6,32,77]. } \\
\text { Relatively slow printing speeds [77] } \\
\text { Increased friability [6,77]. } \\
\text { Potential microbial contamination of the semisolid ink [115]. } \\
\text { Potential need for drying or curing procedures[115]. }\end{array}$ \\
\hline
\end{tabular}

Stereolithography (SLA)

\begin{tabular}{|c|c|}
\hline Advantages & Drawbacks \\
\hline $\begin{array}{l}\text { Highest accuracy and resolution, with } \\
\text { deci-micron layer thickness }[6,73] \text {. } \\
\text { Most suitable for micro delivery devices } \\
\text { [32]. }\end{array}$ & $\begin{array}{l}\text { Most photopolymers used are potential carcinogens and there is a limited array of biocompatible } \\
\text { ones [6,77]. } \\
\text { Free radicals are produced following the curing of the polymer using laser/UV light [57]. } \\
\text { Some APIs could be degraded by the UV light employed in SLA [32,77]. } \\
\text { SLA printers don't usually employ polymer mixtures, and the addition of APIs could prove } \\
\text { challenging, especially for elevated doses [77]. Current research limits the drug loading to just } \\
6 \% \text { dissolved API in the photopolymer solution, yet, for non-pharmaceutical applications, SLA } \\
\text { has been used to produce parts containing } 53 \% \text { suspended particles [77]. For the same reasons, } \\
\text { multi-drug, multi-compartment devices could prove difficult to attain [77]. } \\
\text { SLA is a slow printing process, with } 1-3 \mathrm{~cm} / \mathrm{h} \text { printing speeds (although the more recent CLIP } \\
\text { technology can reach } 100 \mathrm{~cm} / \mathrm{h} \text { ), with consequent post-printing curing time required [6]. }\end{array}$ \\
\hline \multicolumn{2}{|l|}{ Selective Laser Sintering (SLS) } \\
\hline Advantages & Drawbacks \\
\hline $\begin{array}{l}\text { Solvent free process; no subsequent } \\
\text { drying [25]. } \\
\text { Internal porosity is highly controllable } \\
\text { [6]. }\end{array}$ & $\begin{array}{l}\text { Limited array of excipients and APIs that are not degraded by the laser energy }[6,77] \text {. } \\
\text { Slow process, with printing speeds between } 1-5 \mathrm{~cm} / \mathrm{h}[6,77] \text {. } \\
\text { Post-processing is usually required in order to remove the powder residue adhering to the printed } \\
\text { part }[6,77] . \\
\text { Large amounts of powder waste are generated }[6,77] . \\
\text { Higher costs by comparison to the other methods }[77] \text {. }\end{array}$ \\
\hline
\end{tabular}


FARMACIA, 2018, Vol. 66, 3

\begin{tabular}{|c|c|}
\hline \multicolumn{2}{|l|}{ Binder jetting } \\
\hline Advantages & Drawbacks \\
\hline $\begin{array}{l}\text { Larger array of appropriate materials [6]. } \\
\text { Room temperature operation [6]. } \\
\text { Easier production of porous structures } \\
\text { when compared to traditional } \\
\text { manufacturing [6]. } \\
\text { High dose flexibility [106]. }\end{array}$ & $\begin{array}{l}\text { The printed structures have an increased fragility due to high porosity }[6,57,77] \text {. } \\
\text { Low resolution method [6,77]. } \\
\text { Increased risk of agglomeration towards the center of the printed structure [77]. } \\
\text { Elevated post-printing drying times [6]. } \\
\text { Significant wastage of the unbound powders [6]. } \\
\text { API stability may be problematic in liquid ink media [106]. }\end{array}$ \\
\hline \multicolumn{2}{|l|}{ Drop on demand jet printing (DOD) } \\
\hline Advantages & Drawbacks \\
\hline $\begin{array}{l}\text { Increases bioavailability of poorly } \\
\text { soluble drugs [45]. } \\
\text { Nano-scale precision dosing [95]. } \\
\text { Enables printing down to picoliter } \\
\text { precision [15]. }\end{array}$ & $\begin{array}{l}\text { The printer needs to be used regularly, otherwise the printhead nozzles dry up and clogging } \\
\text { occurs [21,32,70]. } \\
\text { Clogging of the print head may also arise due to nucleation or crystal development in } \\
\text { supersaturated solutions [95]. } \\
\text { Satellite drop formation is an undesired issue determined by a combination of factors, both ink } \\
\text { and hardware dependant }[87,95] \text {. } \\
\text { Too fast or too slow solvent evaporation [95]. } \\
\text { Usually, only low drug loadings can be attained, especially for the newly discovered, mostly } \\
\text { poorly soluble drugs [7,15,32], though greater drug loadings may be achieved by nanoparticle } \\
\text { complexes suspensions that are able to generate supersaturation [15]. } \\
\text { Touching of the printhead to the substrate may lead to smearing of the drug ink, thus causing } \\
\text { unexpected doses in the final printlet [7]. } \\
\text { API stability may be problematic in liquid ink media [106]. }\end{array}$ \\
\hline
\end{tabular}

\section{Future challenges}

The 3D printing process needs optimisation and increased versatility, including the choice of multiple materials for excipients [70].

Prerequisites include thorough understanding of the chemical and physical properties of the API and excipients, naming just a few: surface tension, viscosity, rheology or powder wettability $[46,70]$. Current GMP regulations need to be taken into account in order to design a process that complies to the required quality production practices [46].

\section{Conclusions}

With so much interest and research found in the past few years, 3D printing in pharmaceutics has reached an impressive rhythm of development and promises great progress in the future.

Pharmaceutical 3DP is a highly interdisciplinary endeavour that includes many experts from the fields of software and hardware development, polymer engineering, pharmaceutical sciences, biology and medicine [32].

The advent of a new industrial revolution within pharmaceutical technology will most certainly include 3DP [106], and the constant progress in research and development in polymer science will probably be the determinant for new 3DP bulk materials [114].

When comparing 3DP methods, even if the only approved 3D printed drug is made using BJ, FDM is more versatile, cheaper and less wasteful when preparing small-scale, patient tailored medicines $[65,102]$.
Reports indicate up to $80 \%$ of adverse drug reactions are dose related, with 100,000 registered deaths of hospitalised US patients per year due to adverse drug reactions, while patients' response to the same dose of medication can range between 400 to $4000 \%$ [18].

The highest demand for dose personalisation is for pediatric and geriatric patients or for specific drugs like opiates or hormones [7,81].

3DP is a simple, cost-effective way of manufacturing personalised oral medicines and other drug devices [66].

Polypills can be printed using different API loaded filaments or inks, resulting in tablets containing customised API combinations with different doses and release profiles of the same API, making them suitable for individualised drug therapy $[43,62,65]$.

The production of common prosthesis that would replace limbs, joints, eyes, teeth or jaw bone is increasingly facile and cheaper using 3DP, rather than traditional methods, especially for pediatric patients that need recurrent enlargement of the pieces [108].

3D printing showed better accuracy and repeatability for drug coating medical implants when compared to regular drug spray coating [83].

It is not likely that 3DP will become the universal production method of choice, but instead it may become the primary method for certain drugs or therapies, especially at the point of care [24].

For most of the newly discovered drugs, water solubility is usually limited, hence the possibility of forming amorphous solid dispersions when blended with the excipients is highly advantageous and this 
FARMACIA, 2018, Vol. 66, 3

could be correlated to the miscibility of the drug and the polymeric systems [102].

Even though there is obvious interest and progress in the field, the large-scale introduction of 3DP pharmaceutical products may be delayed mainly due to legal and regulatory issues [77]. On the other hand, there is no indication that drug-loaded filaments will be commercially available in the near future [86].

Once the technical, safety and legal issues are clarified, 3DP has the potential of becoming the method of choice for the manufacture of individual drug combinations, orphan drugs or poorly soluble drugs [86].

Conventional dispensing could shift from traditional standardisation to $3 \mathrm{D}$ printing machines, which could be employed as a type of "dynamic dose dispenser" [79].

All rules and regulations applicable to traditional manufacturing processes, must also be applicable to 3DP medicines, so quality and safety can be assured, regardless of the manufacturing location, be it either the hospital, the pharmacy or indeed an industrial site [86]. The 3D printers used for drug manufacturing should follow pharmaceutical GMP standards and regulations $[77,106]$.

Even if 3DP technologies are more expensive than conventional ones, the efficiency of the treatments could reduce the healthcare long term, overall costs.

The prospect of STL file sharing will be beneficial for the researchers who wish to verify and replicate the results of others [40].

While the type of 3DP hardware that is selected is essential, software is compulsory, as no 3D printer can be operated without using the appropriate software. Other professionals like architects or engineers are surely accustomed to CAD software, but health professionals are rarely familiar to them, so special training must be provided and university curriculums should include such themes, at least for post-graduate programs.

\section{References}

1. www.accessdata.fda.gov/drugsatfda_docs/label/2017/ 207958s004lbl.pdf

2. www.spritam.com/pdfs/spritam-medication-guide.pdf

3. www.wbur.org/radioboston/2017/01/13/mit-3d-printing

4. Acosta-Vélez GF, Linsley CS, Craig MC, Wu BM, Photocurable Bioink for the Inkjet 3D Pharming of Hydrophilic Drugs, Bioengineering, 2017, 4(11): 1-11, doi.org/10.3390/bioengineering4010011

5. Alhijjaj M, Belton P, Qi S, An investigation into the use of polymer blends to improve the printability of and regulate drug release from pharmaceutical solid dispersions prepared via fused deposition modeling (FDM) 3D printing, European Journal of Pharmaceutics and Biopharmaceutics, 2016, 108: 111-125, doi.org/10.1016/j.ejpb.2016.08.016

6. Alhnan MA, Okwuosa TC, Sadia M, Wan K-W, Ahmed W, Arafat B, Emergence of 3D Printed Dosage Forms:
Opportunities and Challenges, Pharm Res, 2016, 33: 18171832, doi.org/10.1007/s11095-016-1933-1

7. Alomari M, Mohamed FH, Basit AW, Gaisford S, Personalised dosing: Printing a dose of one's own medicine, International Journal of Pharmaceutics, 2015, 494: 568-577, doi.org/10.1016/j.ijpharm.2014.12.006

8. Beck RCR, Chaves PS, Goyanes A, Vukosavljevic B, Buanz A, Windbergs M, Basit AW, Gaisford S, 3D printed tablets loaded with polymeric nanocapsules: An innovative approach to produce customized drug delivery systems, International Journal of Pharmaceutics, 2017, 528: 268-279, doi.org/10.1016/j.ijpharm.2017.05.074

9. Boehm RD, Miller PR, Daniels J, Stafslien S, Narayan RJ, Inkjet printing for pharmaceutical applications, Materials Today, 2014, 247-252, doi.org/10.1016/j.mattod.2014.04.027

10. Boehm RD, Miller PR, Schell WA, Perfect JR, Narayan RJ, Inkjet Printing of Amphotericin B onto Biodegradable Microneedles Using Piezoelectric Inkjet Printing, The Journal of The Minerals, Metals \& Materials Society, 2013, 65(4): 525-533, doi.org/10.1007/s11837-013-0574-7

11. Boetker J, Water JJ, Aho J, Arnfast L, Bohr A, Rantanen $\mathrm{J}$, Modifying release characteristics from $3 \mathrm{D}$ printed drugeluting products, European Journal of Pharmaceutical Sciences, 2016, 90: 47-52, doi.org/10.1016/j.ejps.2016.03.013 12. Bourell D, Kruth JP, Leu M, Levy G, Rosen D, Beese AM, Clare A, Materials for additive manufacturing, CIRP Annals - Manufacturing Technology, 2017, 66: 659-681, doi.org/10.1016/j.cirp.2017.05.009

13. Buanz ABM, Belaunde CC, Soutari N, Tuleu C, Gul MO, Gaisford S, Ink-jet printing versus solvent casting to prepare oral films: Effect on mechanical properties and physical stability, International Journal of Pharmaceutics, 2015, 494: 611-618, doi.org/10.1016/j.ijpharm.2014.12.032

14. Chai X, Chai H, Wang X, Yang J, Li J, Zhao Y, Cai W, Tao T, Xiang X, Fused Deposition Modeling (FDM) 3D Printed Tablets for Intragastric Floating Delivery of Domperidone, Scientific Reports, 2017, 7: 1-9, doi.org/10.1038/s41598-017-03097-x

15. Cheow WS, Kiew TY, Hadinoto K, Combining inkjet printing and amorphous nanonization to prepare personalized dosage forms of poorly-soluble drugs, European Journal of Pharmaceutics and Biopharmaceutics, 2015, 96: 314-321, doi.org/10.1016/j.ejpb.2015.08.012

16. Chua $\mathrm{CK}$, Wong $\mathrm{CH}$, Yeong WY, Introduction to $3 \mathrm{D}$ Printing or Additive Manufacturing in: Standards, Quality Control, and Measurement Sciences in 3D Printing and Additive Manufacturing, ISBN: 978-0-12-813489-4, 2017, 129, doi.org/10.1016/B978-0-12-813489-4.00001-5

17. Clark EA, Alexander MR, Irvine DJ, Roberts CJ, Wallace MJ, Sharpe S, Yoo J, Hague RJM, Tuck CJ, Wildman RD, 3D printing of tablets using inkjet with UV photoinitiation, International Journal of Pharmaceutics, 2017, 529: 523-530, doi.org/10.1016/j.ijpharm.2017.06.085

18. Cohen JS, Ways to minimize adverse drug reactions, Postgraduate Medicine, 1999, 106(3): 163-172, doi.org/10.3810/pgm.1999.09.688

19. Daly R, Harrington TS, Martin GD, Hutchings IM, Inkjet printing for pharmaceutics - A review of research and manufacturing, International Journal of Pharmaceutics, 2015, 494: 554-567, doi.org/10.1016/j.jpharm.2015.03.017 20. Economidou SN, Lamprou DA, Douroumis D, 3D printing applications for transdermal drug delivery, 
FARMACIA, 2018, Vol. 66, 3

International Journal of Pharmaceutics, 2018, 544(2): 415424, doi.org/10.1016/j.ijpharm.2018.01.031

21. Edinger M, Bar-Shalom D, Sandler N, Rantanen J, Genina N, QR encoded smart oral dosage forms by inkjet printing, International Journal of Pharmaceutics, 2018, 536(1): 138-145, doi.org/10.1016/j.ijpharm.2017.11.052 22. Ehtezazi T, Algellay M, Islam Y, Roberts M, Dempster NM, Sarker SD, The Application of 3D Printing in the Formulation of Multilayered Fast Dissolving Oral Films, Journal of Pharmaceutical Sciences, 2018, 107(4): 10761085, doi.org/10.1016/j.xphs.2017.11.019

23. Farah S, Anderson DG, Langer R, Physical and mechanical properties of PLA, and their functions in widespread applications - A comprehensive review, Advanced Drug Delivery Reviews, 2016, 107: 367-392, doi.org/10.1016/j.addr.2016.06.012

24. Fina F, Goyanes A, Gaisford S, Basit AW, Selective laser sintering (SLS) 3D printing of medicines, International Journal of Pharmaceutics, 2017, 529: 285-293, doi.org/10.1016/j.ijpharm.2017.06.082

25. Fina F, Madla CM, Goyanes A, Zhanga J, Gaisford S, Basit AW, Fabricating 3D printed orally disintegrating printlets using selective laser sintering, International Journal of Pharmaceutics, 2018, 541: 101-107, doi.org/10.1016/j.ijpharm.2018.02.015

26. Gbureck U, Vorndran E, Müller FA, Barralet JE, Low temperature direct 3D printed bioceramics and biocomposites as drug release matrices, Journal of Controlled Release, 2007, 122: 173-180, doi.org/10.1016/j.jconrel.2007.06.022

27. Genina N, Boetker JP, Colombo S, Harmankaya N, Rantanen J, Bohr A, Anti-tuberculosis drug combination for controlled oral delivery using 3D printed compartmental dosage forms: From drug product design to in vivo testing, Journal of Controlled Release, 2017, 268: 40-48, doi.org/10.1016/j.jconrel.2017.10.003

28. Genina N, Holländer J, Jukarainenc H, Mäkilä E, Salonen J, Sandler N, Ethylene vinyl acetate (EVA) as a new drug carrier for 3D printedmedical drug delivery devices, European Journal of Pharmaceutical Sciences, 2016, 90: 5363, doi.org/10.1016/j.ejps.2015.11.005

29. Genina N, Janßen EM, Breitenbach A, Breitkreutz J, Sandler N, Evaluation of different substrates for inkjet printing of rasagiline mesylate, European Journal of Pharmaceutics and Biopharmaceutics, 2013, 85: 1075-1083, doi.org/10.1016/j.ejpb.2013.03.017

30. Gibson I, Rosen D, Stucker B, Additive Manufacturing Technologies - 3D Printing, Rapid Prototyping, and Direct Digital Manufacturing, ISBN: 978-1-4939-2112-6, 2015, doi.org/10.1007/978-1-4939-2113-3

31. Gioumouxouzis CI, Katsamenis OL, Bouropoulos N, Fatouros DG, 3D printed oral solid dosage forms containing hydrochlorothiazide for controlled drug delivery, Journal of Drug Delivery Science and Technology, 2017, 40: 164-171, doi.org/10.1016/j.jddst.2017.06.008

32. Goole J, Amighi K, 3D printing in pharmaceutics: A new tool for designing customized drug delivery systems, International Journal of Pharmaceutics, 2016, 499: 376-394, doi.org/10.1016/j.ijpharm.2015.12.071

33. Goyanes A, Buanz ABM, Basit AW, Simon Gaisford S, Fused-filament 3D printing (3DP) for fabrication of tablets, International Journal of Pharmaceutics, 2014, 476: 88-92, doi.org/10.1016/j.ijpharm.2014.09.044

34. Goyanes A, Changa H, Sedougha D, Hattona GB, Wanga J, Buanz A, Simon Gaisford S, Basit AW, Fabrication of controlled-release budesonide tablets via desktop (FDM) 3D printing, International Journal of Pharmaceutics, 2015, 496: 414-420, doi.org/10.1016/j.jpharm.2015.10.039

35. Goyanes A, Det-Amornrat U, Wanga J, Basit AW, Gaisford S, 3D scanning and 3D printing as innovative technologies for fabricating personalized topical drug delivery systems, Journal of Controlled Release, 2016, 234: 41-48, doi.org/10.1016/j.jconrel.2016.05.034

36. Goyanes A, Fernández-Ferreiro A, Majeed A, GomezLado N, Awad A, Luaces-Rodríguez A, Gaisford S, Aguiard $\mathrm{P}$, Basit AW, PET/CT imaging of 3D printed devices in the gastrointestinal tract of rodents, International Journal of Pharmaceutics, 2018, 536: 158-164, doi.org/10.1016/j.ijpharm.2017.11.055

37. Goyanes A, Fina F, Martorana A, Sedough D, Gaisford S, Basit AW, Development of modified release 3D printed tablets (printlets) with pharmaceutical excipients using additive manufacturing, International Journal of Pharmaceutics, 2017, 527: 21-30, doi.org/10.1016/j.ijpharm.2017.05.021

38. Goyanes A, Kobayashi M, Martínez-Pacheco R, Gaisford S, Basit AW, Fused-filament 3D printing of drug products: Microstructure analysis and drug release characteristics of PVA-based caplets, International Journal of Pharmaceutics, 2016, 514: 290-295, doi.org/10.1016/j.ijpharm.2016.06.021

39. Goyanes A, Martinez PR, Buanz A, Basit AW, Gaisford $\mathrm{S}$, Effect of geometry on drug release from 3D printed tablets, International Journal of Pharmaceutics, 2015, 494: 657-663, doi.org/10.1016/j.ijpharm.2015.04.069

40. Gross BC, Erkal JL, Lockwood SY, Chen C, Spence DM, Evaluation of 3D Printing and Its Potential Impact on Biotechnology and the Chemical Sciences, Analytical Chemistry, 2014, 86: 3240-3253, doi.org/10.1021/ac403397r 41. Han YL, Hu J, Genin GM, Lu TJ, Xu F, BioPen: direct writing of functional materials at the point of care, Scientific Reports, 2014, 4: 1-5, doi.org/10.1038/srep04872

42. Hashmi S (editor), Comprehensive Materials Processing, ISBN: 978-0-08-096532-1, 2014

43. Horst DJ, 3D Printing of Pharmaceutical Drug Delivery Systems, Arc Org Inorg Chem Sci, 2018, 1(2): 1-5,

44. Huang SH, Liu P, Mokasdar A, Hou L, Additive manufacturing and its societal impact: a literature review, Int $J$ Adv Manuf Technol, 2013, 67: 1191-1203, doi.org/10.1007/s00170-012-4558-5

45. Içten E, Purohit HS, Wallace C, Giridhar A, Taylor LS, Nagy ZK, Reklaitis GV, Dropwise additive manufacturing of pharmaceutical products for amorphous and self emulsifying drug delivery systems, International Journal of Pharmaceutics, 2017, 524: 424-432, doi.org/10.1016/j.ijpharm.2017.04.003

46. Jamróz W, Kurek M, Łyszczarz E, Brniak W, Jachowicz R, Printing Techniques: Recent Developments in Pharmaceutical Technology, Acta Poloniae Pharmaceutica, 2017, 74(3): 753-763,

47. Jamróz W, Kurek M, Łyszczarz E, Szafraniec J, KnapikKowalczuk J, Syrek K, Paluch M, Jachowicz R, 3D printed orodispersible films with Aripiprazole, International Journal of Pharmaceutics, 2017, 533: 413-420, doi.org/10.1016/j.ijpharm.2017.05.052

48. Janusziewicz R, Tumbleston JR, Quintanilla AL, Mecham SJ, DeSimone JM, Layerless fabrication with continuous liquid interface production, $P N A S, 2016,113(42)$ : 1170311708, doi.org/10.1073/pnas.1605271113 
FARMACIA, 2018, Vol. 66, 3

49. Kamran M, Saxena A, A Comprehensive Study on 3D Printing Technology, MIT International Journal of Mechanical Engineering, 2016, 16(2): 63-69,

50. Kashif M, Yun B, Lee K-S, Chang YW, Biodegradable shape-memory poly(e-caprolactone)/polyhedral oligomeric silsequioxane nanocomposites:sustained drug release and hydrolytic degradation, Materials Letters, 2016, 166: 125128, doi.org/10.1016/j.matlet.2015.12.051

51. Kempin W, Baden A, Weitschies W, Seidlitz A, Glycerol gelatin for 3D-printing of implants using a paste extrusion technique, Current Directions in Biomedical Engineering, 2017, 3(2): 389-392,

52. Kempin W, Franz C, Koster L-C, Schneider F, Bogdahn M, Weitschies W, Seidlitz A, Assessment of different polymers and drug loads for fused deposition modeling of drug loaded implants, European Journal of Pharmaceutics and Biopharmaceutics, 2017, 115: 84-93, doi.org/10.1016/j.ejpb.2017.02.014

53. Khaled SA, Alexander MR, Wildman RD, Wallace MJ, Sharpe S, Yood J, Roberts CJ, 3D extrusion printing of high drug loading immediate release paracetamol tablets, International Journal of Pharmaceutics, 2018, 538: 223-230, doi.org/10.1016/j.ijpharm.2018.01.024

54. Khaled SA, Burley JC, Alexander MR, Roberts CJ, Desktop 3D printing of controlled release pharmaceutical bilayer tablets, International Journal of Pharmaceutics, 2014, 461: 105-111, doi.org/10.1016/j.ijpharm.2013.11.021

55. Khaled SA, Burley JC, Alexander MR, Yang J, Roberts $\mathrm{CJ}$, 3D printing of tablets containing multiple drugs with defined release profiles, International Journal of Pharmaceutics, 2015, 494: 643-650, doi.org/10.1016/j.ijpharm.2015.07.067

56. Khaled SA, Burley JC, Alexander MR, Yang J, Roberts CJ, 3D printing of five-in-one dose combination polypill with defined immediate and sustained release profiles, Journal of Controlled Release, 2015, 217: 308-314, doi.org/10.1016/j.jconrel.2015.09.028

57. Konta AA, García-Piña M, Serrano DR, Personalised 3D Printed Medicines: Which Techniques and Polymers Are More Successful?, Bioengineering, 2017, 4(79): 1-16, doi.org/10.3390/bioengineering4040079

58. Korte C, Quodbach J, Formulation Development and Process Analysis of Drug-loaded Filaments manufactured via Hot-Melt Extrusion for 3D-Printing of Medicines, Pharmaceutical Development and Technology, 2018, in press doi.org/10.1080/10837450.2018.1433208

59. Kyobula M, Adedeji A, Alexander MR, Saleh E, Wildman R, Ashcroft I, Gellert PR, Roberts CJ, 3D inkjet printing of tablets exploiting bespoke complex geometries for controlled and tuneable drug release, Journal of Controlled $\begin{array}{lll}\text { Release, 2017, 207-215, } & \text { 201: }\end{array}$ doi.org/10.1016/j.jconrel.2017.06.025

60. Lee BK, Yun YH, Choi JS, Choi YC, Kim JD, Cho YW, Fabrication of drug-loaded polymer microparticles with arbitrary geometries using a piezoelectric inkjet printing system, International Journal of Pharmaceutics, 2012, 427: 305-310, doi.org/10.1016/j.ijpharm.2012.02.011

61. Lee J-Y, An J, Chua CK, Fundamentals and applications of 3D printing for novel materials, Applied Materials Today, 2017, 7: 120-133, doi.org/10.1016/j.apmt.2017.02.004

62. Lepowsky E, Tasoglu S, 3D printing for drug manufacturing: A perspective on the future of pharmaceuticals, Int $J$ Bioprint, 2018, 4(1): 119, doi.org/10.18063/IJBv4i1.119
63. Li Q, Wen H, Jia D, Guan X, Pan H, Yang Y, Yu S, Zhu $\mathrm{Z}$, Xiang R,Pan $\mathrm{W}$, Preparation and investigation of controlled-release glipizide novel oral device with threedimensional printing, International Journal of Pharmaceutics, 2017, 525: 5-11, doi.org/10.1016/j.ijpharm.2017.03.066

64. Liang K, Carmone S, Brambilla D, Leroux J-C, 3D printing of a wearable personalized oral delivery device: A first-in-human study, Sci. $A d v$., 2018, 4(5): 1-11, doi.org/10.1126/sciadv.aat2544

65. Lim SH, Chia SMY, Kang L, Yap KY-L, ThreeDimensional Printing of Carbamazepine Sustained-Release Scaffold, Journal of Pharmaceutical Sciences, 2016, 105: 2155-2163, doi.org/10.1016/j.xphs.2016.04.031

66. Long J, Gholizadeh H, Lu J, Bunt C, Seyfoddin A, Application of Fused Deposition Modelling (FDM) Method of 3D Printing in Drug Delivery, Curr Pharm Des., 2017, 23(3):

433-439,

doi.org/10.2174/1381612822666161026162707

67. Markl D, Zeitler JA, Rasch C, Høtoft Michaelsen M, Müllertz A, Rantanen J, Rades T, Bøtker J, Analysis of 3D Prints by X-ray Computed Microtomography and Tetrahertz Pulsed Imaging, Pharmaceutical Research, 2017, 34(5): 1037-1052, doi.org/10.1007/s11095-016-2083-1

68. Maroni A, Melocchi A, Parietti F, Foppoli A, Zema L, Gazzaniga A, 3D printed multi-compartment capsular devices for two-pulse oral drug delivery, Journal of Controlled Release, 2017, 268: 10-18, doi.org/10.1016/j.jconrel.2017.10.008

69. Martinez PR, Goyanes A, Basit AW, Gaisford S, Fabrication of drug-loaded hydrogels with stereolithographic 3D printing, International Journal of Pharmaceutics, 2017, 532: 313-317 doi.org/10.1016/j.ijpharm.2017.09.003

70. Maulvi FA, Shah MJ, Solanki BS, Patel AS, Soni TG, Shah DO, Application of 3D Printing Technology in the Development of Novel Drug Delivery Systems, International Journal of Drug Development and Research, 2017, 9(1): 4449 ,

71. Melocchi A, Parietti F, Loreti G, Maroni A, Gazzaniga A, Zema L, 3D printing by fused deposition modeling (FDM) of a swellable/ erodible capsular device for oral pulsatile release of drugs, Journal of Drug Delivery Science and Technology, 2015, 30: 360-367, doi.org/10.1016/j.jddst.2015.07.016

72. Miller SA, Sustainable Polymers: Opportunities for the Next Decade, ACS MAcro Letters, 2013, 2: 550-554, doi.org/10.1021/mz400207g

73. Norman J, Madurawe RD, Moore CMV, Khan MA, Khairuzzaman A, A new chapter in pharmaceutical manufacturing: 3D-printed drug products, Advanced Drug Delivery Reviews, 2017, 108: 39-50, doi.org/10.1016/j.addr.2016.03.001

74. Okwuosa TC, Pereira BC, Arafat B, Cieszynska M, Isreb A, Alhnan MA, Fabricating a Shell-Core Delayed Release Tablet Using Dual FDM 3D Printing for Patient-Centred Therapy, Pharm Res, 2017, 34: 427-437, doi.org/10.1007/s11095-016-2073-3

75. Okwuosa TC, Stefaniak D, Arafat B, Isreb A, Wan K-W, Alhnan MA, A Lower Temperature FDM 3D Printing for the Manufacture of Patient-Specific Immediate Release Tablets, Pharm Res, 2016, 33: 2704-2712, doi.org/10.1007/s11095016-1995-0

76. Oropallo W, Piegl LA, Ten challenges in 3D printing, Engineering with Computers, 2016, 32: 135-148, doi.org/10.1007/s00366-015-0407-0 
FARMACIA, 2018, Vol. 66, 3

77. Palo M, Holländer J, Suominen J, Yliruusi J, Sandler N, 3D printed drug delivery devices: perspectives and technical challenges, Expert Review of Medical Devices, 2017, in press doi.org/10.1080/17434440.2017.1363647

78. Park K, Drug delivery of the future: Chasing the invisible gorilla, Journal of Controlled Release, 2016, 240: 2-8, doi.org/10.1016/j.jconrel.2015.10.048

79. Pietrzak K, Isreb A, Alhnan MA, A flexible-dose dispenser for immediate and extended release 3D printed tablets, European Journal of Pharmaceutics and Biopharmaceutics, 2015, $\quad$ 96: 380-387, doi.org/10.1016/j.ejpb.2015.07.027

80. Pinkerton AJ, Lasers in additive manufacturing, Optics \& Laser Technology, 2016, 78: 25-32, doi.org/10.1016/j.optlastec.2015.09.025

81. Planchette $\mathrm{C}$, Pichler $\mathrm{H}$, Wimmer-Teubenbacher $\mathrm{M}$, Gruber M, Gruber-Woelfler H, Mohr S, Tetyczka C, Hsiao W-K, Paudel A, Roblegg E, Khinast J, Printing medicines as orodispersible dosage forms: Effect of substrate on the printed micro-structure, International Journal of Pharmaceutics, 2016, 509: 518-527, doi.org/10.1016/j.ijpharm.2015.10.054 82. Popescu D, Cazacu A, ECDL 3D Printing: competențe digitale în domeniul modelării 3D și al tehnologiilor de imprimare 3D ISBN: 978-606-94433-0-9, 2017, 5-40

83. Prasad LK, Smyth H, 3D Printing technologies for drug delivery: a review, Drug Development and Industrial Pharmacy, 2016, 42(7): 1019-1031, doi.org/10.3109/03639045.2015.1120743

84. Preim B, Bartz D, Visualization in Medicine: Theory, Algorithms, And Applications, ISBN: 978-0-12-370596-9, 2007

85. Preis M, Breitkreutz J, Sandler N, Perspective: Concepts of printing technologies for oral film formulations, International Journal of Pharmaceutics, 2015, 494: 578-584, doi.org/10.1016/j.ijpharm.2015.02.032

86. Preis M, Öblom1 H, 3D-Printed Drugs for Children - Are We Ready Yet?, AAPS PharmSciTech, 2017, 18(2): 303-308, doi.org/10.1208/s12249-016-0704-y

87. Qi S, Craig D, Recent developments in micro- and nanofabrication techniques for the preparation of amorphous pharmaceutical dosage forms, Advanced Drug Delivery Reviews, 2016, 100: 67-84, doi.org/10.1016/j.addr.2016.01.003

88. Ramot Y, Haim-Zada M, Domb AJ, Nyska A, Biocompatibility and safety of PLA and its copolymers, Advanced Drug Delivery Reviews, 2016, 107: 153-162, doi.org/10.1016/j.addr.2016.03.012

89. Redwood B, Schöffer F, Garret B, The 3D Printing Handbook. Technologies, design and applications, ISBN: 978-9082748505, 2017

90. Ren X, Shao H, Lin T, Zheng H, 3D gel-printing - An additive manufacturing method for producing complex shape parts, Materials and Design, 2016, 101: 80-87, doi.org/10.1016/j.matdes.2016.03.152

91. Roitman LA, Shanks M, The new Industrial Revolution: manufacturing with 3D Printers and Polymer Materials in an Economy of Design, Innovation and Intellectual Property, International Journal of Economics \& Management Sciences, 2016, 6(1): 1-7, doi.org/10.4172/2162-6359.1000391

92. Sadia M, Arafat B, Ahmed W, Forbes RT, Alhnan MA, Channelled tablets: An innovative approach to accelerating drug release from 3D printed tablets, Journal of Controlled Release, 2018, 269: 355-363, doi.org/10.1016/j.jconrel.2017.11.022
93. Sadia M, Sosnicka A, Arafat B, Isreb A, Ahmed W, Kelarakis A, Alhnan MA, Adaptation of pharmaceutical excipients to FDM 3D printing for the fabrication of patienttailored immediate release tablets, International Journal of Pharmaceutics, 2016, 513: 659-668, doi.org/10.1016/j.ijpharm.2016.09.050

94. Salmoria GV, Klauss P, Zepon K, Kanis LA, Roesler CRM, Vieira LF, Development of functionally-graded reservoir of PCL/PG by selective laser sintering for drug delivery devices, Virtual and Physical Prototyping, 2012, 7(2): 107-115, doi.org/10.1080/17452759.2012.687911

95. Scarpa M, Stegemann S, Hsiao WK, Pichler H, Gaisford S, Bresciani M, Paudel A, Orlu M, Orodispersible films: Towards drug delivery in special populations, International Journal of Pharmaceutics, 2017, 523: 327-335, doi.org/10.1016/j.ijpharm.2017.03.018

96. Schneider C, Langer R, Loveday L, Hair D, Applications of ethylene vinyl acetate copolymers (EVA) in drug delivery systems, Journal of Controlled Release, 2017, 262: 284-295, doi.org/10.1016/j.jconrel.2017.08.004

97. Scoutaris N, Alexander MR, Gellert PR, Roberts CJ, Inkjet printing as a novel medicine formulation technique, Journal of Controlled Release, 2011, 156: 179-185, doi.org/10.1016/j.jconrel.2011.07.033

98. Scoutaris N, Ross SA, Douroumis D, 3D Printed "Starmix" Drug Loaded Dosage Forms for Paediatric Applications, Pharmaceutical Research, 2018, 35(34): 1-11, doi.org/10.1007/s11095-017-2284-2

99. Scoutaris N, Snowden M, Douroumis D, Taste masked thin films printed by jet dispensing, International Journal of Pharmaceutics, 2015, 494: 619-622, doi.org/10.1016/j. ijpharm.2015.05.018

100. Shogrena RL, Doane WM, Garlotta D, Lawton JW, Willett JL, Biodegradation of starch/polylactic acid/poly(hydroxyester-ether) composite bars in soil, Polymer Degradation and Stability, 2003, 79: 405-411,

101. Skowyra J, Pietrzak K, Alhnan MA, Fabrication of extended-release patient-tailored prednisolone tablets via fused deposition modelling (FDM) 3D printing, European Journal of Pharmaceutical Sciences, 2015, 68: 11-17, doi.org/10.1016/j.ejps.2014.11.009

102. Solanki NG, Tahsin Md, Shah AV, Serajuddin ATM, Formulation of 3D Printed Tablet for Rapid Drug Release by Fused Deposition Modeling: Screening Polymers for Drug Release, Drug-Polymer Miscibility and Printability, Journal of Pharmaceutical Sciences, 2018, 107: 390-401, doi.org/10.1016/j.xphs.2017.10.021

103. Tagami T, Fukushige K, Ogawa E, Hayashi N, Ozeki T, 3D Printing Factors Important for the Fabrication of Polyvinylalcohol Filament-Based Tablets, Biol. Pharm. Bull., 2017, 40(3): 357-364, doi.org/10.1248/bpb.b16-00878

104. The British Standards Institution, Additive manufacturing - General principles - Terminology (ISO/ASTM 52900), ISBN: 9780580919374, 2016

105. Tong R, Gabrielson NP, Fan TM, Cheng J, Polymeric nanomedicines based on poly(lactide) and poly(lactide-coglycolide), Current Opinion in Solid State and Materials Science, 2012, 16: 323-332, doi.org/10.1016/j.cossms.2013.01.001

106. Trenfield SJ, Awad A, Goyanes A, Gaisford S, Basit AW, 3D Printing Pharmaceuticals: Drug Development to Frontline Care, Trends in Pharmacological Sciences, 2018, 39(5): 440-451, doi.org/10.1016/j.tips.2018.02.006 
FARMACIA, 2018, Vol. 66, 3

107. Verstraete G, Samaro A, Grymonpré W, Vanhoorne V, Van Snick B, Boone MN, Hellemans T, Van Hoorebeke L, Remon JP, Vervaet C, 3D printing of high drug loaded dosage forms using thermoplastic polyurethanes, International Journal of Pharmaceutics, 2018, 536: 318-325, doi.org/10.1016/j.ijpharm.2017.12.002

108. Vijayavenkataraman S, Fuh JYH, Lu WF, 3D Printing and 3D Bioprinting in Pediatrics, Bioengineering, 2017, 4(63): 1-11, doi.org/10.3390/bioengineering4030063

109. Wang J, Goyanes A, Gaisford S, Basit AW, Stereolithographic (SLA) 3D printing of oral modified-release dosage forms, International Journal of Pharmaceutics, 2016, 503: 207-212, doi.org/10.1016/j.ijpharm.2016.03.016

110. Wickström H, Palo M, Rijckaert K, Kolakovic R, Nyman JO, Määttänen A, Ihalainen P, Peltonen J, Genina N, De Beer T, Löbmann K, Rades T, Sandler N, Improvement of dissolution rate of indomethacin by inkjet printing, European Journal of Pharmaceutical Sciences, 2015, 75: 91-100, doi.org/10.1016/j.ejps.2015.03.009

111. Wischke C, Neffe AT, Steuer S, Lendlein A, Evaluation of a degradable shape-memory polymer network as matrix for controlled drug release, Journal of Controlled Release, 2009, 138: 243-250, doi.org/10.1016/j.jconrel.2009.05.027

112. Wu BM, Borland SW, Giordano RA, Cima LG, Sachs EM, Cima MJ, Solid free-form fabrication of drug delivery devices, Journal of Controlled Release, 1996, 40: 77-87, 113. Yi H-G, Choi Y-J, Kang KS, Hong JM, Pati RG, Park MN, Shim IK, Lee CM, Kim SC, Cho D-W, A 3D-printed local drug delivery patch for pancreatic cancer growth suppression, Journal of Controlled Release, 2016, 238: 231241, doi.org/10.1016/j.jconrel.2016.06.015

114. Yu DG, Zhu L-M, Branford-White CJ, Yang XL, ThreeDimensional Printing in Pharmaceutics: Promises and Problems, Journal of Pharmaceutical Sciences, 2008, 27(9): 3666-3690, doi.org/10.1002/jps.21284
115. Zema L, Melocchi A, Maroni A, Gazzaniga A, ThreeDimensional Printing of Medicinal Products and the Challenge of Personalized Therapy, Journal of Pharmaceutical Sciences, 2017, 106: 1697-1705, doi.org/10.1016/j.xphs.2017.03.021

116. Içten, Giridhar A, Taylor LS, Nagy ZK, Reklaitis GV, Dropwise Additive Manufacturing of Pharmaceutical Products for Melt-Based Dosage Forms, Pharmaceutics, Drug Delivery and Pharmaceutical Technology, 2015, 104(5): 1641-1649, doi.org/10.1002/jps.24367

117. Genina N, Fors D, Palo M, Peltonen J, Sandler N, Behavior of printable formulations of loperamide and caffeine on different substrates-Effect of print density in inkjet printing, International Journal of Pharmaceutics, 2013, 453: 488-497, doi.org/10.1016/j.ijpharm.2013.06.003

118. Melocchi A, Parietti F, Maroni A, Foppoli A, Gazzaniga A, Zema L, Hot-melt extruded filaments based on pharmaceutical grade polymers for 3D printing by fused deposition modeling, International Journal of Pharmaceutics, 2016, 509: 255-263, doi.org/10.1016/j.ijpharm.2016.05.036

119. Yang Y, Wang H, Li H, Ou Z, Yang G, 3D printed tablets with internal scaffold structure using ethyl cellulose to achieve sustained ibuprofen release, European Journal of Pharmaceutical Sciences, 2018, 115: 11-18, doi.org/10.1016/j.ejps.2018.01.005

120. Goyanes A, Buanz ABM, Hatton GB, Gaisford S, Basit AW, 3D printing of modified-release aminosalicylate (4-ASA and 5-ASA) tablets, European Journal of Pharmaceutics and Biopharmaceutics, 2015, 89: 157-162, doi.org/10.1016/j.ejpb.2014.12.003

121. Zhang J, Yang W, Vo AQ, Feng X, Ye X, Kim DW, Repka MA, Hydroxypropyl methylcellulose-based controlled release dosage by melt extrusion and 3D printing: Structure and drug release correlation, Carbohydrate Polymers 2017, 177: 49-57, doi.org/10.1016/j.carbpol.2017.08.058 